\title{
SHP2 inhibition enhances the anticancer effect of Osimertinib in EGFR T790M mutant lung adenocarcinoma by blocking CXCL8 loop mediated stemness
}

\section{Leiming Xia ( $\sim 278461175 @ q q . c o m)$}

Anhui Medical University https://orcid.org/0000-0002-6760-0153

Fan Yang

Anhui Medical University

Suzhi Li

Anhui Medical University

\section{Chen Kan}

Anhui Medical University

Hong Zheng

Anhui Medical University

Siying Wang

Anhui Medical University

\section{Primary research}

Keywords: SHP2, T790M mutation, lung adenocarcinoma, CXCL8 feedback loop, stemness, Osimertinib

Posted Date: March 4th, 2021

DOl: https://doi.org/10.21203/rs.3.rs-262045/v1

License: (c) (i) This work is licensed under a Creative Commons Attribution 4.0 International License.

Read Full License 


\section{Abstract}

Background: Additional epidermal growth factor receptor (EGFR) mutations confer the drug resistance to generations of EGFR targeted tyrosine kinase inhibitor (EGFR-TKI), which is the thorny challenge to propel the treatment of lung adenocarcinoma (LUAD) forward. In the tailored targeting era, the strategy of EGFRTKI combined regimen was considered the promising approach to conquer the big aforesaid question. The mechanism of SHP2 involved in the cell proliferation, cytokine production, stemness maintenance and drug resistance of LUAD was not yet fully explored.

Methods: To determine the impact of SHP2 on the efficacy of EGFR T790M mutant LUAD cells to Osimertinib, SHP2 was tested in Osimertinib treated LUAD cells. Cell proliferation and stemness were tested in SHP2 modified LUAD cells. RNA sequencing were performed to explore the mechanism of SHP2 promoted stemness.

Results: This study demonstrated that high SHP2 indicates poor outcome of LUAD patients, and enriched in Osimertinib resistant LUAD cells. Moreover, SHP2 inhibition suppressed the cell proliferation and damaged the stemness of EGFR T790M mutant LUAD. Furthermore, SHP2 facilitates the CXCL8 secretion of EGFR T790M mutant LUAD which derived from a CXCL8-CXCR1/2 positive feedback loop that promoted the stemness and tumorigenesis. Finally, we found SHP2 inhibited ERK-AKT-NFKB and GSK3 $\beta-\beta$ Catenin pathways in EGFR T790M mutant LUAD cells, inactivation of NF-KB confers to a blockage of CXCL8-CXCR1/2 loop, and stemness limited by restricting GSK3 $\beta / \beta$-Catenin signaling.

Conclusions: Our data revealed that inhibition of SHP2 enhances the anti-cancer effect of Osimertinib in EGFR T790M mutant LUAD by blocking CXCL8-CXCR1/2 loop mediated stemness, which may provide an alternative option to promote the efficacy of osimertinib in clinic of EGFR T790M mutant LUAD.

\section{Introduction}

Lung cancer is the primary cause of cancer related incidence and mortality worldwide[1], and lung adenocarcinoma (LUAD) is the most prevalent histological subtype[2-4]. The characterization of LUAD is more precision in nowadays that due to the achievement of gain-of-function mutations on epidermal growth factor receptor (EGFR)[5]. EGFR mutation plays a critical role in regulating the malignancy of lung cancer cells, and East Asian LUAD patients are harboring the highest mutation rate of EGFR[6-9].

Revolutionized mutant EGFR targeted tyrosine kinase inhibitors (EGFR-TKIs) have impressively improved the clinical outcome of LUAD patients[10, 11]. However, additional T790M mutation confers half of the acquired resistant cases that treated under $1^{\text {st }}$ generation EGFR-TKIs which occurs in 8-14 months[12-15]. Furthermore, updated data reported that around $43.16 \%$ T790M mutant patients who were resistant to $3^{\text {rd }}$ generation TKI, Osimertinib, which is specifically targeting the ATP site of EGFR with T790M mutation[1618]. Thus, exploring of effective approaches is required urgently for treatment of T790M mutant LUAD patients. Therapies combined with Osimertinib were preferred currently which can significantly inhibit tumor progression, reverse even Osimertinib resistance[19, 20]. 
Cancer stem cells (CSCs) were characterized by the sub-population that are endowed with capacity of tumor initiation[21], disease recurrence[22] and cancer dissemination[23-25], especially the aggressive drug resistance[26, 27]. CD133 was identified as an important stemness marker for LUAD[28], and CSCs targeting therapies were reported that could reverse the drug resistance[29]. SHP2 (Src homology 2containing phosphotyrosine phosphatase 2 ) plays a critical role in regulating $\operatorname{CSCs}[30,31]$ and cytokine release[32-34]. Secreted cytokine feedback loop serves an important role in maintaining the stemness of progenitor cells[35-37]. CXCL8 promotes the formation of tumor micro-environment (TME)[38] and the enrichment of CSCs[39-41]. More importantly, CXCL8 secret loop facilitates the re-population of drug resistant cancer cells which largely disputed the outcome in clinic[42, 43], the resistance could be inverted with CXCL8 inhibition[43].

To our acknowledgement, whether SHP2 confers the drug resistance to EGFR-TKIs through cancer stemness is largely unknown currently, which is valuable in clinic. Herein, we hypothesized that SHP2 inhibition could sensitize the T790M mutant LUAD to osimertinib via stemness suppression by blocking the autocrine CXCL8 feedback loop, and potentially ameliorate the prognosis of EGFR T790M mutant LUAD patients.

\section{Materials And Methods}

\section{Cell Lines and Reagents}

The PC9 (Del19) and PC9GR (T790M\&Del19 mutant) LUAD cell lines were generously granted from Dr. Changzhi Xu (Anhui University, Hefei, China). Both PC9 and PC9GR cells were cultured in DMEM medium supplemented with $10 \% \mathrm{FBS}, 100 \mathrm{U} / \mathrm{mL}$ penicillin and $100 \mathrm{mg} / \mathrm{mL}$ streptomycin, and incubated in $5 \%$ $\mathrm{CO}_{2}$ at $37^{\circ} \mathrm{C}$.

Lv-SHP2, Lv-SHP2-RNAI (RNA interference) and scrambled controls were recruited from Shanghai Genechem Co.,Ltd.. Recombinant human EGF (SRP3027) and FGF (GF003AF) were purchased from Sigma-Aldrich. SHP2 inhibitor (SHP099, Cat\#: HY-100388), recombinant human CXCL8 (Cat\#: HYP7224), CXCR2 inhibitor (Danirixin, Cat\#:HY-19768), CXCR1/2 inhibitor (Reparixin, CAT\#: HY-15251) and Osimertinib (AZD-9291, Cat\#: HY-15772) were bought from MCE LLC. Human CXCL8 Immunoassay Quantikine ELISA Kit (Cat\#:D8000C) was acquired from R\&D Systems.

Antibodies against SHP2(Clone:D50F2, Cat\#:3397), CD133(Clone:D2V8Q, Cat\#:64326), GSK3ß(Clone:D5C5Z, Cat\#:12456), p-GSK3ß(ser9) (Clone:5B3, Cat\#:9323), $\beta$ Catenin(Clone:D10A8, Cat\#:8480), ERK1/2(Clone:137F5, Cat\#:4695), p-ERK1/2(Thr202/Tyr204) (Clone:20G11, Cat\#:4376), AKT(Clone:11E7, Cat\#:4685), p-AKT(Ser473) (Clone:D9E, Cat\#:4060), p-RelA/p65(Ser536) (Clone:93H1, Cat\#:3033), p-lkBß(Thr19/Ser23) (Cat\#:4921), Ki67(Clone:D2H10, Cat\#:9027) and $\beta$-actin (Clone:8H10D10, Cat\#:3700) were purchased from Cell Signaling Technology. For Flow assays, antiCD133 monoclonal antibody conjugated with Super Bright 436 (Clone:TMP4, Cat\#:62-1338-42), and mouse IgG1 kappa Isotype Control (Cat\#:62-4714-42) were from eBioscience. 


\section{Lentiviral Transduction}

Lentiviral transduction was performed following user`s protocol using GV298 plasmids encoding overexpression (Ubi-MCS-3FLAG-CBh-gcGFP-IRES-puromycin) and RNAI (U6-MCS-Ubiquitin-Cherry-IRESpuromycin) against SHP2 and homologous control. Briefly, $1 \times 10^{5}$ cells were seeded in 6 well plate and incubated overnight. $20 \mu \mathrm{L}$ of $1 \times 10^{8} \mathrm{TU} / \mathrm{mL}$ lentivirus diluted in $1 \mathrm{~mL}$ complete DMEM medium was added into each well, and medium changed after incubated for another 12 hours. Fluorescence expression was used for monitoring the efficacy of transfection. Infected PC9 and PC9GR cells were selected by puromycin $(0.5 \mu \mathrm{g} / \mathrm{ml})$ for 7 days to generate the stable clones and maintained in $0.3 \mu \mathrm{g} / \mathrm{mL}$ of puromycin condition over 1 month.

Transcriptome Analyses based on next-generation sequencing (NGS)

In order to analyze the relevant gene transcription of SHP2 modification in LUAD, the NGS of lentivirus modified and parental PC9GR cells were performed by the Beijing Genome Institute (BGI, Shenzhen, China). Total RNA was extracted, mRNA was enriched and then the cDNA libraries were prepared. Transcriptome expression were generated by equal quantities of RNA from lentivirus modified and parental PC9GR cells, 3 biological duplications were repeated in each group. Bowtie2 (v2.2.5) was applied to align the clean reads to the gene set, a database for this organism built by BGI, which known and novel, coding transcripts were included, then expression level of gene was calculated by RSEM (v1.2.12). The heatmap was drawn by pheatmap (v1.0.8) according to the gene expression in different samples. To take insight to the change of phenotype, KEGG (https://www.kegg.jp/) enrichment analysis of annotated different expression gene was performed by Phyper based on Hypergeometric test. The significant levels of terms and pathways were corrected by $Q$ value with a rigorous threshold ( $Q$ value $\leq 0.05$ ) by Bonferroni.

\section{Bioinformatics Analysis}

The online Kaplan-Meier analysis of the overall survival (OS) and progression free survival (PFS) of all 719 LUAD patients with different SHP2 and other EGFR downstream genes expression were performed by the Kaplan-Meier Plotter (http://kmplot.com/analysis/) with the auto select best cutoff of patients sectionalization for significance was set to $p<0.001[44]$.

\section{Cell Viability testing by MTT assay}

Cell Viability was tested by MTT assay. Briefly, $2 \times 10^{3}$ cells were seeded in each well of 96 -well plates with $200 \mu \mathrm{L}$ medium and incubated for time that indicated in the text. Then, $50 \mu \mathrm{MTT}$ solution was added to the bottom of wells. Supernatant discarded after 4 hours incubation, MTT formazan crystal was then dissolved in DMSO, and the absorbance was measured by a Multi-Mode Microplate Reader (Varioskan Flash, Thermo Scientific) at a wavelength of $490 \mathrm{~nm}$.

\section{Colony formation}


For soft agar colony formation testing, $1.5 \mathrm{ml}$ of $0.6 \%$ agarose was filled into the wells of 6 -well plate and solidified in fume hood for 30 mins. lentivirus transduced and parental PC9, PC9GR cells were washed with phosphate buffered saline (PBS) and 2000 cells were suspended in $0.35 \%$ top agarose in DMEM supplemented with $10 \%$ FBS and plated on top of the bottom agarose. Clones were scored after 2 weeks of incubation.

For colony formation assays, lentivirus transduced PC9, PC9GR and parental cells were washed with PBS and plated at a cell density of 200 cells per well in DMEM supplemented with or without treatment, and clones were fixed with crystal violet and scored after 2 weeks of incubation.

\section{Tumorsphere formation}

For tumorsphere formation assays, lentivirus transduced and parental PC9, PC9GR cells were seeded in $1.2 \%$ agarose pre-coated 6-well plates at a density of $2000 / \mathrm{ml}$ in serum free DMEM/F12 medium (Gibco) with $10 \mathrm{ng} / \mathrm{mL}$ bFGF, $20 \mathrm{ng} / \mathrm{mL}$ EGF. The culture medium was changed every 2 days until the sphere generated. After 7 to 10 days culturing, the spheres were collected for further experiments.

\section{Flow Cytometry Testing}

$1 \times 10^{6}$ cells $/ 100 \mu \mathrm{L}$ was aliquot into FACS tubes. Added $5 \mu \mathrm{L}$ anti-CD133 antibody into each tube and vortex. And then incubated for 30 minutes at room temperature in the dark on ice. After centrifuging the suspended cells at $300 \mathrm{xg}$ for 5 minutes, decant the buffer and re-suspend the cells with $2 \mathrm{~mL}$ of flow cytometry staining buffer. Repeat the wash for two times. Re-suspend the cells in $400 \mu \mathrm{L}$ of buffer for analysis (BD Bioscience, San Jose, CA, USA). Data was analyzed in FlowJo Software version 7.6 (Tree Star, Inc., Ashland, OR).

\section{Elisa assay}

For ELISA analysis, $5 \times 10^{4}$ lentivirus transduced PC9, PC9GR and parental cells were seeded in 6-well plates for 48 hours. Culture supernate was collected to quantify the secreted CXCL8 using pre-coated ELISA kit according to the manufacturer's protocol. Briefly, prepared CXCL8 dilute standard solution, sample or control $(100 \mu \mathrm{L})$ was added to each well, and incubated at room temperature for 2 hours. After aspirated and washed each well four times with wash buffer, $100 \mu \mathrm{L}$ of CXCL8 conjugate was added into each well and incubated for 1 hour at room temperature. After four washes, $200 \mu \mathrm{L}$ of substrate solution was added to each well and the plate was incubate for 30 minutes at room temperature in dark. 50 $\mathrm{L}$ of stop solution was added to each well, and then determined the optical density of each well using a microplate reader set to $450 \mathrm{~nm}$. A standard curve was created for figuring the concentration of CXCL8.

\section{Western Blotting}

Cell were lysed in protein lysis buffer containing protease and phosphatase inhibitors. Protein concentration was determined by the BCA Protein Assay Kit. Equal proteins were separated using electrophoresis by SDS-PAGE gels, and transferred to PVDF membrane. After blocking in 5\% milk, PVDF 
membranes were incubated with specific antibodies against to targeted molecule,respectively. The bands were detected with enhanced chemiluminescence and quantified by Image $\mathrm{J}$ software.

\section{Immunohistochemistry (IHC)}

For IHC examination, the tumors from homologous group were harvested, fixed, embedded in paraffin and examined for the further expression of the indicated proteins. Briefly, paraffin-embedded slides were dehydrated and antigen retrieved. Endogenous peroxidase was quenched by treatment with $3 \%$ hydrogen peroxide for 5 minutes. CD133, Ki67 were stained following the manufacturer`s protocol.

\section{Animal Ethics}

The animal protocols were approved by the Anhui Medical University Animal Care \& Use Committee and conducted in accordance with the Guideline for laboratory animals of Anhui Medical University. Balb/c Nude mice were obtained from GemPharmtech Co., Ltd. (Nanjing, Jiangsu) and bred in SPF animal room with a positive pressure containment rack.

\section{Tumorigenicity of SHP2 modified LUAD tumor cells in gradient concentration}

Tumor cells were suspended into indicated solution $(5 \times 104,5 \times 103$ and $5 \times 102)$, and mixed with Matrigel (BD Biosciences) at the ratio of 1:1, injected into the lower flanks of 5 weeks Balb/c-Nude mice subcutaneously. The mice were monitored 2-3 times per week.

\section{Xenograft model}

For testing the sensitivity of PC9 and PC9GR cells to Osimertinib. $1 \times 10^{7}$ cells were injected subcutaneously into the lower flanks of healthy 5 weeks old nude mice. Mice that bearing same tumor were randomly treated with DMSO and Osimertinib $(5.0 \mathrm{mg} / \mathrm{kg}$ daily by oral gavage, S.C., 2 times/week for 3 week), treatment was began in the second week. The mice were monitored 2-3 times per week, and tumor curve was evaluated by formula: [length $\left.\times(\text { width })^{2}\right] / 2$.

For testing the sensitivity of SHP2 high and low expressed PC9GR cells to Osimertinib. $1 \times 10^{7}$ cells were injected subcutaneously into the lower flanks of healthy 5 weeks old nude mice. Mice that bearing same tumor were randomly treated with DMSO and Osimertinib $(5.0 \mathrm{mg} / \mathrm{kg}$ daily by oral gavage, S.C., 2 times/week for 3 week), treatment was began in the second week. The mice were monitored 2-3 times per week, and tumor curve was evaluated by formula: [length $\left.\times(\text { width })^{2}\right] / 2$.

To identify the tumor formation ability of PC9GR Lv-SHP2 and LV-SHP2RNAI cells in the condition of wild type and blockade of CXCL8-CXCR1/2. $1 \times 10^{7}$ cells were collected in PBS and injected S.C. into the lower flanks of healthy 5 weeks old nude mice. Mice that bearing same tumor were randomly separated in three groups, DMSO group, Danirixin (25mg/Kg, S.C., 3 times per week for 3 week) and Reparixin group $(30 \mathrm{mg} / \mathrm{Kg}$, S.C., 3 times per week for 3 week), the treatment was began in the second week. The mice were monitored 2-3 times per week, and tumor curve was evaluated by formula: [length $\left.\times(\text { width })^{2}\right] / 2$. 


\section{Statistical Analysis}

Data in current experiment were represented by means \pm SEM. For comparison between two groups, statistical significance was performed by Student's t-test, For comparison of more than two groups, statistical significance was performed by ANOVA. Statistical analyses were performed with GraphPad Prism 7 software. $p$ values of $<0.05$ are considered statistically significant.

\section{Results}

\section{Higher expression of SHP2 indicates poor survival and Osimertinib resistance in LUAD patients.}

To determine whether SHP2 participates in regulating disease progression and Osimertinib resistance in LUAD patients, we firstly assessed the prognostic differences of LUAD patients harboring distinct levels of SHP2 mRNA. To this end, combined dataset (data from TCGA, GSE and CAARRAY) including 2437 LUAD patients were analyzed by the online tool (http://kmplot.com/analysis/)[44]. High SHP2 mRNA expression of LAUD patients suffered poor overall survival (OS) (71.27 months v.s. 112.67 months, $p=0.00062)$ and progression free survival (PFS) (21.3 months v.s. 37 months, $p=0.00019)$ than low expressed patients, which indicated that SHP2 involved in tumor progression of LUAD (Figure 1A). Meanwhile, downstream key molecules of EGFR signaling were evidenced that SHP2 was talent showing itself. Generally we found high mRNA expression of genes in MEK-ERK and PI3K-AKT pathways was also associated with poor outcome of LUAD (Supplementary Figure 1). Next, we hypothesized whether SHP2 expression is associated with Osimertinib sensitivity in LUAD cells. We investigated the half maximal inhibitory concentration (IC50) of PC9 and PC9GR cells respectively, and tested the SHP2 protein in residual cells that treated with Osimertinib of IC50 (Figure 1B). Here, we reported that SHP2 expression was much higher in PC9GR cells than PC9 cells, and malignant LUAD cells contain higher SHP2 than BEAS-2B pulmonary epithelial cells. Also, SHP2 was enriched in corresponding IC50 of Osimertinib treated PC9GR and PC9 cells, which means SHP2 might mediate Osimertinib resistance in T790M mutant LUAD (Figure 1C). Further, we generated PC9 and PC9GR bearing mice and found that higher SHP2 protein expressed in the tumor of Osimertinib treated tumor was than that of DMSO group (Figure 1D). Here, we supposed that high SHP2 related to poor outcome of LUAD patients, and the SHP2 was enriched in Osimertinib resistant T790M mutant LUAD cells.

\section{SHP2 reduce the sensitivity of T790M mutant LUAD cells to Osimertinib.}

To identify whether SHP2 plays an essential role in mediating Osimertinib resistance of T790M mutant LUAD, we tested the response of SHP2 modified LUAD cells to Osimertinib. Firstly, we generated a stable SHP2 transfected LUAD cells, lenti-viral plasmids harboring SHP2 (Lv-SHP2) and SHP2 RNA interference (Lv-SHP2RNAI) was transfected into both PC9 and PC9GR cells. Lv-SHP2 plasmids were labeled in green, and Lv-SHP2RNAI plasmids in red, and SHP2 testing confirmed SHP2 modified cells were established successfully (Figure 2A). Next, we investigated the relationship between SHP2 and Osimertinib sensitivity in T790M mutant LUAD cells. We found that co-cultured with Osimertinib for 72 hours, the viability of PC9 
and PC9GR cells with high SHP2 were significantly higher than that of their parental cells in a dose dependent manner, while the SHP2 knock down cells were inhibited than that of their parents (Figure 2B). High SHP2 expressed PC9 and PC9GR cells formed substantially larger residual crystal violet than that of their parental cells when co-cultured with Osimertinib, while the residual crystal violet generated by SHP2 knocked down cells was obviously decreased (Figure 2C). Therefore, the in vitro data showed that the proliferation of PC9GR cells with high SHP2 expression was significantly stronger than that of their parental cells in medium supplemented with Osimertinib, while SHP2 inhibition attenuates the proliferation of PC9GR cells. In vivo data suggested that Osimertinib dramatic shrunk the tumor size of PC9GR tumor (Figure 2D), Osimertinib reduced 55.96\% tumor weight of SHP2 over-expressed tumors to $0.710 \mathrm{~g}$ from $1.612 \mathrm{~g}$ in control, and in SHP2 inhibited arm Osimertinib suppressed $89.51 \%$ tumor weight to $0.138 \mathrm{~g}$ from $1.316 \mathrm{~g}$ (Figure 2E). In IHC assay, the percentage of Ki67 positive cells in LV-SHP2RNAI PC9GR tumor was decreased than LV-SHP2 PC9GR tumor treated with Osimertinib. More importantly, the proportion of CD133 positive CSCs was much higher in LV-SHP2 PC9GR tumor than LV-SHP2RNAI tumor in Osimertinib administration (Figure 2F). Therefore, SHP2 over-expressed PC9GR cells showed significant Osimertinib resistance than SHP2 inhibited cells which might be through enhancement of cell proliferation and CSCs enrichment.

\section{SHP2 inhibition suppressed the proliferation of LUAD cells.}

To test whether SHP2 mediated the malignant proliferation of LUAD cells. Firstly, we analyzed the cell viability of parental and SHP2 modified lenti-virus transfected PC9 and PC9GR cells treated with SHP2 inhibitor-SHP099, the data showed that SHP099 could significantly inhibit the proliferation of PC9 and PC9GR cells in time and dose dependent manner. We found that the IC50 of SHP099 in PC9 cells was 20.100 and 7.536 at 4 and 24 hours, respectively (Figure 3A), and the IC50 of SHP099 in PC9GR cells was 24.670 and 8.900 at 4 and 24 hours, respectively (Figure 3B). Further, we investigated the tendency of SHP2 derived proliferation in PC9 and PC9GR cells after culturing for 24 and 48 hours, and SHP2 overexpressed PC9GR and PC9 cells showed aggressive proliferation than SHP2 inhibited cells after whether 24 or 48 hours (Figure $3 C \&$ D). Similarly, colony formation assay showed that larger residual clones were established by PC9 and PC9GR cells with high expression of SHP2 compared with parent cell lines, while smaller residual clones were established in PC9 and PC9GR cells with low expression of SHP2 (Figure 3E). These data upheld the role of SHP2 in regulating the proliferation of LUAD with EGFR T790M mutation which was unveiled in Figure 2, and the parallel variation of $\mathrm{CD}_{133^{+}} \mathrm{CSC}$ s in Osimertinib treated tumors need further identify.

\section{The stemness of LUAD cells were damaged by SHP2 inhibition.}

To test whether SHP2 involved in regulating CSCs of LUAD that promoted the malignant biology, we evaluated the percentage and stemness of SHP2 modified cells. We found that the percentage of CD133 ${ }^{+}$ CSCs increased from $7.013 \pm 0.560 \%$ of parental PC9GR cells to $11.767 \pm 0.801 \%$ of SHP2 over-expressed cells, the proportion of $\mathrm{CD} 133^{+}$CSCs decreased to $2.973 \pm 0.346 \%$ in SHP2 knock down cells. Meanwhile, CD $133^{+}$LUAD CSCs in SHP2 over-expressed PC9 cells increased from $3.697 \pm 0.092 \%$ of parental cells to 
$8.370 \pm 0.607 \%$, while the proportion of $\mathrm{CD}_{133^{+}}$CSCs decreased to $1.467 \pm 0.319 \%$ when knock down SHP2 (Figure 4A). We likewise observed the role of SHP2 plays in mediating biology of CSCs in LUAD. In soft Agar culturing, PC9 and PC9GR cells with high SHP2 formed bigger and productive spheres than homologous parental cells in gel, while low SHP2 expressed cells showed impaired ability to train spheres (Figure 4B). Similarly, in sphere formation, PC9 and PC9GR cells with high SHP2 formed bigger and more spheres than their parent cells, while low SHP2 expressed PC9 and PC9GR cells had a significantly attenuated ability to train spheres (Figure 4C). Further, we detected the proportion of $\mathrm{CD}^{133^{+}}$cells in the sphere on the 7th day in order to figure out the SHP2 high cells generated bigger sphere was derived by CSCs accumulation. After 7 days culturing, the proportion of CSCs in SHP2 high expressed PC9GR cells was significantly enriched from $10.410 \pm 0.506 \%$ of the parental cells to $64.833 \pm 2.188 \%$, and the CSCs of low SHP2 expressed PC9GR cells was also significantly enriched after 7 days which increased from $2.910 \pm 0.260 \%$ of the parental cells to $46.267 \pm 1.933 \%$. However, high SHP2 derived CSCs enrichment of PC9GR cell was considerably be found, and similar evidence was also observed in PC9 cells (Figure 4D). In addition we tested the tumorigenesis of SHP2 high, low LUAD cells, 50000, 5000 and 500 high and low SHP2 modified PC9 and PC9GR cells were inoculated into Balb/c-Nu nude mice, respectively, and the SHP2 cells showed aggressive capability of tumor generation which was presented in Figure 4E, and the tumorigenesis rate was described (Supplementary Table 1). For the mechanism analyzing, we applied transcriptome sequencing in SHP2 modified PC9GR cells and 1,203 variable genes across the datasets were identified for clustering which was highlighted the stem cell pathway (Supplementary Figure 2). As determined by western blotting testing of GSK3 $\beta-\beta C$ Catenin pathway, phosphorylated protein of GSK3 $\beta$ and $\beta$ Catenin were validly reduced in low SHP2 PC9GR cells (Figure 4F). Thus, it can be concluded that up-regulated SHP2 substantially enhanced the proportion and function of CSCs in LUAD which might be the potential mechanism for Osimertinib resistance.

\section{SHP2 facilitates the CXCL8 secretion of EGFR T790M mutant LUAD.}

We found that SHP2 promoted the enhancement of stemness in EGFR T790M mutant LUAD, and to the best of our knowledge, secreted cytokines in tumor microenvironment (TME) were essential for the stemness regulation and maintenance[45, 46]. In order to further clarify the key cytokines of SHP2 mediated proportion and function of CSCs, we enriched the differently expressed mRNA in inhibited, overexpressed and parental PC9GR cells in plot of secreted signaling molecule, 32 significant genes were selected including CXCL8 (Figure 5A and Supplementary Table 2). We selected CXCL8, IL-6 and TGF- $\beta 1$, which are deemed to be related to the regulation and maintenance of CSCs. The mRNA expression of CXCL8 and IL-6 genes showed significant diversity among the three groups, while TGF- $\beta 1$ mRNA was not significantly altered. Meanwhile the correlation analysis implied a significant correlation coefficient of $r=0.9253$ between CXCL8 and SHP2, the relationship of IL-6 and SHP2 was conferred a r $=0.8501$ (Figure 5B). Then, we detected the concentration of CXCL8 in the supernatant of parental and SHP2 modified PC9GR cells. The concentration of CXCL8 in the culture medium of high SHP2 expressed PC9GRcells was significantly higher than that of parental cells, while the CXCL8 in the supernatant of SHP2 inhibited PC9GR cells was significantly reduced. CXCL8 was founded significantly curbed in PC9GR Lv-SHP2RNAI 
cells comparing with parental and Lv-SHP2 transfected cells, and the results were repeatable and credible (Figure 5C). To illustrated the SHP2 derived cytokine secretion, we classified the transcriptome expression and found the different genes were largely enriched in MAPK and stem pathways (Supplementary Figure 2). We monitored the prototype and phosphorylated molecule in EGFR downstream NF-KB signaling. The activated ERK, AKT and RelA/p65 were significantly up-regulated in high SHP2 modified cells than parental cells, and parallelly down-regulated in SHP2 inhibited cells (Figure 5D). These data suggest that SHP2 plays a critical role in CXCL8 secretion of LUAD via ERK-AKT-NFKB pathway, which could effective modulate a positive CXCL8-CXCR1/2 feedback loop that might promote stemness and Osimeitinib resistance.

\section{SHP2 inhibition suppresses the stemness and tumorigenesis of EGFR T790M mutant LUAD by CXCL8/CXCR1 positive feedback loop.}

To investigate whether SHP2 derived CXCL8 can promote a CXCL8-CXCR1/2 feedback loop, we treated parental and SHP2 modified PC9GR cells with CXCR2 inhibitor-Danirixin, CXCR1/2 inhibitor-Reparixin and human recombinant CXCL8 to imitate the blockage and facilitation of feedback loop, respectively. We tested the colony formation of SHP2 modified PC9GR cells treated with the CXCL8-CXCR1/2 blockage and facilitation, the clones were dramatically skewed by Danirixin or Reparixin, while exogenous CXCL8 significantly enhanced the clone formation of PC9GR (Figure 6A). Furthermore, we found that the percentage of CSCs was reduced in the setting of CXCL8-CXCR1/2 loop blockage, and recombinant CXCL8 could reverse the CSCs proportion (Figure 6B). In SHP2 over-expressed panel, Danirixin and Reparixin respectively decreased the CSCs to $6.193 \pm 0.875 \%$ and $5.703 \pm 0.419 \%$ from $11.223 \pm 0.738 \%$, however additional CXCL8 raised the CSCs to $14.040 \pm 0.397 \%$. In SHP2 inhibited panel, Danirixin and Reparixin respectively decreased the CSCs to $1.807 \pm 0.309 \%$ and $1.970 \pm 0.471 \%$ from $3.757 \pm 0.237 \%$, but additional CXCL8 increased the CSCs to $7.010 \pm 0.920 \%$. Whereafter, we found CXCL8-CXCR1/2 blockage dramatically restrained the tumor generation of both SHP2 high and low expression PC9GR cells in vivo (Figure 6C). The tumor weight also verified the tumor curve of different groups, CXCL8-CXCR1/2 blockage limit the weight of SHP2 high PC9GR tumors than that of treated with DMSO, which decreased from $2.050 \pm 0.184 \mathrm{~g}$ to $0.850 \pm 0.023 \mathrm{~g}$ and $0.993 \pm 0.070 \mathrm{~g}$, and tumor weight SHP2 inhibited cells reduced from $1.576 \pm 0.116 \mathrm{~g}$ to $0.510 \pm 0.106 \mathrm{~g}$ and $0.474 \pm 0.055 \mathrm{~g}$, respectively (Figure 6D). We summarized the mechanism of the experiment and showed in Figure 7.These data suggest that the blockage of CXCL8/CXCR1 feedback loop could synergistically suppress the stemness and tumorigenesis of SHP2 inhibited PC9GR cells.

\section{Discussion}

Lung cancer is the one of the most serious malignant diseases to imperil human health which leading the principal incidence and mortality around the world[47], and LUAD is the most prevalent histological subtype[2, 48]. Before tailed-targeting era, unfortunate outcome of 5-year DFS and PFS, high recurrence and distant metastasis largely limited the clinical progression of $\operatorname{LUAD}[49,50]$. 
Cognition of EGFR mutation was a stirring milestone on the history of LUAD which is crucial for the occurrence and development[51]. Mutant EGFR can occur abnormal spontaneous downstream signal pathways that promote malignant proliferation and metastasis of LUAD[52], and also is taken into account to be a key reason for the failure of traditional radiotherapy and chemotherapy[53, 54]. Impressively, the prognosis of LUAD patients treated with first-generation EGFR-TKI was revolutionary improved compared with chemotherapy administration, the DFS increased from 5.7 (5.2-6.3) months to 11.9 (9.1-14.6) months, the OS was improved from 24.3 (17.7-30.1) months to 25.8 (21.3-30.2) months, and the response rate was increased from $32.5 \%$ to $65.9 \%$. More interestingly, the EGFR-TKIs combination strategy could further enhance the PFS, OS and response rate to 17.5 months, 32.6 months and $82.5 \%$, respectively[54]. However, all LUAD patients inevitably developed to $1 \mathrm{st}$ EGFR-TKIs resistance within 8-14 months[55], resulting in the progression of the primary disease, $41-62 \%$ of which due to an additional T790M mutation in EGFR[56]. The affinity of EGFR T790M mutation to ATP is dramatically higher than 1st EGFR-TKIs, and reduces the efficacy of drugs[57].

The $3^{\text {rd }}$ generation EGFR-TKIs were designed to specifically binding to EGFR with the T790M mutation, and offered an efficient affinity which could competitively suppress the ATP binding with the kinase domain[17]. In clinic, Osimertinib achieved a significant improvement on the outcome of $1^{\text {st }}$ EGFR-TKIs resistant LUAD patients which represented the vast achievement of $3^{\text {rd }}$ generation EGFR-TKIs. In newly diagnosed EGFR T790M LUAD patients, Osimertinib prolonged the median PFS to 8.2 (6.8-9.7) months, while the patients got 4.2 (4.1-5.1) months who received platinum plus pemetrexed[58]. Osimertinib even could alleviate the LUAD patients who are failed in 1st EGFR-TKIs treatment[59]. However, the most fundamental challenge to Osimertinib is around $66.43 \%$ of patients occurred acquired drug resistance, current reports indicated that some gene mutations like, T790M loss, C797S mutation, KRAS mutation and novel gene fusions were involved in[60].

Recent data suggested that $3^{\text {rd }}$ generation EGFR-TKIs based combination can significantly improve the efficacy in LUAD clinic which is one of the few strategies to enhance sensitivity and reverse resistance[61, 62]. A phase II randomized trial indicated that the appropriate combination regime is especially important. Janne and colleges indicated that advanced EGFR mutant LUAD patients could not benefit from erlotinib and pemetrexed-cisplatin combined treatment[63].

Here, we found SHP2 plays a key role in EGFR T790M mutant LUAD cells that are resistant to Osimertinib. SHP2 was enriched in Osimertinib resistant LUAD cells, and SHP2 inhibition could further boost the killing effect of Osimertinib. We found that residual EGFR T790M mutant LUAD cells after treated with Osimertinib expressed a high level of SHP2 protein, SHP2 low LUAD cells showed more sensitive to Osimertinib than parallel controlled SHP2 high cells in vitro and in vivo. Further inhibition of SHP2 (inhibitor and gene knock down) showed a synergistic effect in proliferative suppression of LUAD cells when combined with Osimertinib. Our findings revealed that blockage of SHP2 and T790M EGFR can be served as a alternative and promising dual targeting strategy in LUAD, actually a bunch of studies have shown that SHP2 inhibitors can synergistically promote the killing effect of several targeted drugs or even overcome the drug resistance[64-66]. SHP2 inhibitors can reverse the sorafenib resistance of 
hepatocellular carcinoma by inhibiting MEK/ERK and AKT signaling[66]. Current studies proved that KRAS mutation and ALK rearrangement non-small cell lung cancer(NSCLC) patients could benefit from SHP2 inhibitor composed combo therapy. Combination administration of SHP2 and MEK inhibitor can markedly suppress the proliferation of KRAS mutant NSCLC[67], and even reverse the drug resistance to first-generation EGFR-TKIs[68]. In ALK rearrangement NSCLC, SHP2 inhibitors combined with ALK inhibitors showed aggressive anti-tumor effects than a single drug in vivo and in vitro, and reverse the resistance of ALK inhibitors[69].

Next, we illuminate the potential mechanism of SHP2 played in deriving the insensitive of LAUD cells to Osimertinib. Multiple independent data identified that SHP2 could up-regulate the proportion and biology of CSCs in various tissues[70-74], and the enrichment of stemness is often related to drug resistance of LC $[75,76]$. Similarly, Jiang et al. Reported that SHP2 inhibitor restrained the expression of stem related marker in KRAS mutant NSCLC, and the function of CSCs formed sphere was significantly inhibited[70]. Our results also firstly reported that the proliferation of SHP2 high EGFR T790M mutant LUAD cells can be significantly enhanced, knock down SHP2 could limited the proliferation and enhanced sensitivity to Osimertinib, simultaneously accompanied by the stemness regulation that be modified by SHP2 derived CXCL8-CXCR1/2 feedback loop. Presently, the mechanism of SHP2 regulating CSCs is focused on the intracellular signaling, such as GSK3 $\beta-\beta$ catenin[71], JUK[77], Wnt[78] and so on. The occurrence and progression of local tumor is the process of balance between proliferation and apoptosis of tumor cells, especially CSCs. CSCs play a vital role in regulating TME which is important to maintain the malignant proliferation[79-82]. However, interleukin from TME could prime a positive feedback loop which is important in stressing the stemness of tumor[83-85].

To the best of our acknowledge, we inventively investigated whether SHP2 could promote tumor stemness via an interleukin feedback loop. We found 32 differential genes among SHP2 gradient modified LUAD cells that were clustered in the set of secreted molecules, and CXCL8 is the key mediator. The supernate of SHP2 high EGFR T790M mutant LUAD cells contained a high concentration of CXCL8 than that of SHP2 low cells. Meanwhile, we discovered that the percentage and biological function of CSCs was strengthened in additional CXCL8 culturing, and reduced when plugging the CXCL8-CXCR1/2 loop. CXCL8 is an important cytokine that secreted by tumor cells, which participates in initiating TME[86, 87], maintaining CSCs function[88-90], and leading drug resistance[91, 92]. Li et al. Reported that SHP2 was parallelly increased with the production of CXCL8 in acute cigarette smoke treated LUAD cells, and CXCL8 secretion decreased when SHP2 was knocked out or selectively inhibited[93]. Interestingly, It has been reported that CXCL8 can induce the resistance of $1^{\text {st }}$ generation of EGFR-TKI by promoting the stemness of LUAD cell line[94]. A clinic trial indicated that the CSCs could be significantly reduced by inhibiting CXCR1/2, CSCs labeled with $\mathrm{ALDH} 1^{+}$and $\mathrm{CD} 44^{+} / \mathrm{CD} 24^{-}$that decreased more than $20 \%$ were monitored in 4/17 and 9/17 evaluable patients after administration of CXCR1/2 inhibitor, respectively[95]. Therefore, we conclude that SHP2 promotes stemness up-regulation in EGFR T790M mutant LUAD cells through CXCL8-CXCR1/2 loop, which is the principal reason for inducing Osimertinib resistance. Furthermore, we analyzed the molecular mechanism that SHP2 related to generating a positive loop, and 
found MAPK signaling was enriched which identified with western blot. Be analogous to our results, Mamik et al. revealed that SHP2 can promote CXCL8 synthesis and secretion by activating p38 and ERK in MAPK pathway in astrocytes[96].

\section{Conclusion}

In brief, we found that inhibition of SHP2 in EGFR T790M mutant LUAD cells can improve the sensitivity of tumor cells to Osimertinib, and the mechanism is that inhibition of SHP2 can suppresses the CSCs by blockade of CXCL8-CXCR1/2 positive feedback loop. This finding provides a theoretical basis for the application of SHP2 inhibitor combined with Osimertinib to enhance the sensitivity of EGFR T790M mutant LUAD cells to Osimertinib and to avoid the occurrence of resistance. For sure, the safety and efficacy of a strategy that combined SHP2 inhibitor with Osimertinib in the treatment of EGFR T790M mutant or Osimertinib resistant LUAD patients have yet to further verified by clinical data.

\section{Declarations}

Conflict of interest statement: We declare that we have no financial and personal relationships with other people or organizations that can inappropriately influence our work, there is no professional or other personal interest of any nature or kind in any product, service and/or company that could be construed as influencing the position presented in, or the review of, the manuscript entitled.

Ethics approval and consent to participate: The animal protocols were approved by the Anhui Medical University Animal Care \& Use Committee and conducted in accordance with the Guideline for laboratory animals of Anhui Medical University. Balb/c Nude mice were obtained from GemPharmtech Co., Ltd. (Nanjing, Jiangsu) and bred in SPF animal room with a positive pressure containment rack.

Consent for publication: Not applicable.

Availability of data and materials: transcriptome sequencing presented as Figure $5 \mathrm{~A}$ and Supplementary Table 2

Competing interests: The authors declare that they have no competing interests.

Funding: This work was supported by by the National Natural Science Foundation of China (81472087).

\section{Authors' contributions:}

Acknowledgements: Not applicable.

\section{References}

1. Bray F, Ferlay J, Soerjomataram I, Siegel RL, Torre LA, Jemal A: Global cancer statistics 2018: GLOBOCAN estimates of incidence and mortality worldwide for 36 cancers in 185 countries. $C A$ 
Cancer J Clin 2018, 68(6):394-424.

2. Arbour KC, Riely GJ: Systemic Therapy for Locally Advanced and Metastatic Non-Small Cell Lung Cancer: A Review. JAMA 2019, 322(8):764-774.

3. Marshall EA, Ng KW, Kung SH, Conway EM, Martinez VD, Halvorsen EC, Rowbotham DA, Vucic EA, Plumb AW, Becker-Santos DD et al: Emerging roles of Thelper 17 and regulatory $\mathrm{T}$ cells in lung cancer progression and metastasis. MOL CANCER 2016, 15(1):67.

4. Travis WD, Brambilla E, Noguchi M, Nicholson AG, Geisinger KR, Yatabe Y, Beer DG, Powell CA, Riely GJ, Van Schil PE et al: International association for the study of lung cancer/american thoracic society/european respiratory society international multidisciplinary classification of lung adenocarcinoma. J THORAC ONCOL 2011, 6(2):244-285.

5. Comprehensive molecular profiling of lung adenocarcinoma. NATURE 2014, 511(7511):543-550.

6. Gahr S, Stoehr R, Geissinger E, Ficker JH, Brueckl WM, Gschwendtner A, Gattenloehner S, Fuchs FS, Schulz C, Rieker RJ et al: EGFR mutational status in a large series of Caucasian European NSCLC patients: data from daily practice. Br J Cancer 2013, 109(7):1821-1828.

7. Chun YJ, Choi JW, Hong MH, Jung D, Son H, Cho EK, Min YJ, Kim SW, Park K, Lee SS et al: Molecular characterization of lung adenocarcinoma from Korean patients using next generation sequencing. PLOS ONE 2019, 14(11):e224379.

8. Coudray N, Ocampo PS, Sakellaropoulos T, Narula N, Snuderl M, Fenyo D, Moreira AL, Razavian N, Tsirigos A: Classification and mutation prediction from non-small cell lung cancer histopathology images using deep learning. NAT MED 2018, 24(10):1559-1567.

9. Li S, Choi YL, Gong Z, Liu X, Lira M, Kan Z, Oh E, Wang J, Ting JC, Ye X et al: Comprehensive Characterization of Oncogenic Drivers in Asian Lung Adenocarcinoma. J THORAC ONCOL 2016, 11(12):2129-2140.

10. Tan CS, Gilligan D, Pacey S: Treatment approaches for EGFR-inhibitor-resistant patients with nonsmall-cell lung cancer. LANCET ONCOL 2015, 16(9):e447-e459.

11. Ramalingam SS, Vansteenkiste J, Planchard D, Cho BC, Gray JE, Ohe Y, Zhou C, Reungwetwattana T, Cheng Y, Chewaskulyong B et al: Overall Survival with Osimertinib in Untreated, EGFR-Mutated Advanced NSCLC. N Engl J Med 2020, 382(1):41-50.

12. Russo A, Franchina T, Ricciardi G, Smiroldo V, Picciotto M, Zanghi M, Rolfo C, Adamo V: Third generation EGFR TKIs in EGFR-mutated NSCLC: Where are we now and where are we going. Crit Rev Oncol Hematol 2017, 117:38-47.

13. Yu HA, Arcila ME, Rekhtman N, Sima CS, Zakowski MF, Pao W, Kris MG, Miller VA, Ladanyi M, Riely GJ: Analysis of tumor specimens at the time of acquired resistance to EGFR-TKI therapy in 155 patients with EGFR-mutant lung cancers. CLIN CANCER RES 2013, 19(8):2240-2247.

14. Sequist LV, Waltman BA, Dias-Santagata D, Digumarthy S, Turke AB, Fidias P, Bergethon K, Shaw AT, Gettinger S, Cosper AK et al: Genotypic and histological evolution of lung cancers acquiring resistance to EGFR inhibitors. SCI TRANSL MED 2011, 3(75):26r-75r. 
15. Langer CJ: Epidermal growth factor receptor inhibition in mutation-positive non-small-cell lung cancer: is afatinib better or simply newer? J CLIN ONCOL 2013, 31(27):3303-3306.

16. Lategahn J, Keul M, Klovekorn P, Tumbrink HL, Niggenaber J, Muller MP, Hodson L, Flasshoff M, Hardick J, Grabe T et al: Inhibition of osimertinib-resistant epidermal growth factor receptor EGFRT790M/C797S. CHEM SCI 2019, 10(46):10789-10801.

17. Piotrowska Z, Isozaki H, Lennerz JK, Gainor JF, Lennes IT, Zhu VW, Marcoux N, Banwait MK, Digumarthy SR, Su W et al: Landscape of Acquired Resistance to Osimertinib in EGFR-Mutant NSCLC and Clinical Validation of Combined EGFR and RET Inhibition with Osimertinib and BLU-667 for Acquired RET Fusion. CANCER DISCOV 2018, 8(12):1529-1539.

18. Oxnard GR, Hu Y, Mileham KF, Husain H, Costa DB, Tracy P, Feeney N, Sholl LM, Dahlberg SE, Redig AJ et al: Assessment of Resistance Mechanisms and Clinical Implications in Patients With EGFR T790M-Positive Lung Cancer and Acquired Resistance to Osimertinib. JAMA ONCOL 2018, 4(11):1527-1534.

19. Combo Therapy Beats Back Relapsed NSCLC. CANCER DISCOV 2019, 9(6):685.

20. To C, Jang J, Chen T, Park E, Mushajiang M, De Clercq D, Xu M, Wang S, Cameron MD, Heppner DE et al: Single and Dual Targeting of Mutant EGFR with an Allosteric Inhibitor. CANCER DISCOV2019, 9(7):926-943.

21. Plaks V, Kong N, Werb Z: The cancer stem cell niche: how essential is the niche in regulating stemness of tumor cells? CELL STEM CELL 2015, 16(3):225-238.

22. Berns A: Stem cells for lung cancer? CELL 2005, 121(6):811-813.

23. Pantel K, Alix-Panabieres C, Riethdorf S: Cancer micrometastases. NAT REV CLIN ONCOL 2009, 6(6):339-351.

24. Hosseini H, Obradovic M, Hoffmann M, Harper KL, Sosa MS, Werner-Klein M, Nanduri LK, Werno C, Ehrl C, Maneck M et al: Early dissemination seeds metastasis in breast cancer. NATURE 2016, 540(7634):552-558.

25. Harper KL, Sosa MS, Entenberg D, Hosseini H, Cheung JF, Nobre R, Avivar-Valderas A, Nagi C, Girnius $\mathrm{N}$, Davis RJ et al: Mechanism of early dissemination and metastasis in Her2(+) mammary cancer. NATURE 2016, 540(7634):588-592.

26. Lytle NK, Barber AG, Reya T: Stem cell fate in cancer growth, progression and therapy resistance. NAT REV CANCER 2018, 18(11):669-680.

27. Hu J, Guan W, Liu P, Dai J, Tang K, Xiao H, Qian Y, Sharrow AC, Ye Z, Wu L et al: Endoglin Is Essential for the Maintenance of Self-Renewal and Chemoresistance in Renal Cancer Stem Cells. STEM CELL REP 2017, 9(2):464-477.

28. Chen J, Chen H, Yang H, Dai H: SPC25 upregulation increases cancer stem cell properties in nonsmall cell lung adenocarcinoma cells and independently predicts poor survival. BIOMED PHARMACOTHER 2018, 100:233-239.

29. Nunes T, Hamdan D, Leboeuf C, El BM, Gapihan G, Nguyen TT, Meles S, Angeli E, Ratajczak P, Lu H et al: Targeting Cancer Stem Cells to Overcome Chemoresistance. INT J MOL SCI 2018, 19(12). 
30. Dong L, Yu WM, Zheng H, Loh ML, Bunting ST, Pauly M, Huang G, Zhou M, Broxmeyer HE, Scadden DT et al: Leukaemogenic effects of Ptpn11 activating mutations in the stem cell microenvironment. NATURE 2016, 539(7628):304-308.

31. Liu X, Yu X, Xie J, Zhan M, Yu Z, Xie L, Zeng H, Zhang F, Chen G, Yi X et al: ANGPTL2/LILRB2 signaling promotes the propagation of lung cancer cells. Oncotarget 2015, 6(25):21004-21015.

32. Pandey R, Saxena M, Kapur R: Role of SHP2 in hematopoiesis and leukemogenesis. CURR OPIN HEMATOL 2017, 24(4):307-313.

33. Dong L, Zheng H, Qu CK: CCL3 is a key mediator for the leukemogenic effect of Ptpn11-activating mutations in the stem-cell microenvironment. BLOOD 2017, 130(12):1471-1474.

34. Xiao P, Guo Y, Zhang H, Zhang X, Cheng H, Cao Q, Ke Y: Myeloid-restricted ablation of Shp2 restrains melanoma growth by amplifying the reciprocal promotion of CXCL 9 and IFN-gamma production in tumor microenvironment. ONCOGENE 2018, 37(37):5088-5100.

35. Valdez JM, Zhang L, Su Q, Dakhova O, Zhang Y, Shahi P, Spencer DM, Creighton CJ, Ittmann MM, Xin L: Notch and TGFbeta form a reciprocal positive regulatory loop that suppresses murine prostate basal stem/progenitor cell activity. CELL STEM CELL 2012, 11(5):676-688.

36. Van den Steen PE, Proost P, Wuyts A, Van Damme J, Opdenakker G: Neutrophil gelatinase B potentiates interleukin-8 tenfold by aminoterminal processing, whereas it degrades CTAP-III, PF-4, and GRO-alpha and leaves RANTES and MCP-2 intact. BLOOD 2000, 96(8):2673-2681.

37. Yeo HL, Fan TC, Lin RJ, Yu JC, Liao GS, Chen ES, Ho MY, Lin WD, Chen K, Chen CH et al: Sialylation of vasorin by ST3Gal1 facilitates TGF-beta1-mediated tumor angiogenesis and progression. INT $J$ CANCER 2019, 144(8):1996-2007.

38. Kawano M, Tanaka K, Itonaga I, Iwasaki T, Tsumura H: Interaction between human osteosarcoma and mesenchymal stem cells via an interleukin-8 signaling loop in the tumor microenvironment. CELL COMMUN SIGNAL 2018, 16(1):13.

39. Ortiz-Montero P, Londono-Vallejo A, Vernot JP: Senescence-associated IL-6 and IL-8 cytokines induce a self- and cross-reinforced senescence/inflammatory milieu strengthening tumorigenic capabilities in the MCF-7 breast cancer cell line. CELL COMMUN SIGNAL 2017, 15(1):17.

40. Tang KH, Ma S, Lee TK, Chan YP, Kwan PS, Tong CM, Ng IO, Man K, To KF, Lai PB et al: CD133(+) liver tumor-initiating cells promote tumor angiogenesis, growth, and self-renewal through neurotensin/interleukin-8/CXCL1 signaling. HEPATOLOGY 2012, 55(3):807-820.

41. Singh JK, Simoes BM, Howell SJ, Farnie G, Clarke RB: Recent advances reveal IL-8 signaling as a potential key to targeting breast cancer stem cells. BREAST CANCER RES2013, 15(4):210.

42. Jia D, Li L, Andrew S, Allan D, Li X, Lee J, Ji G, Yao Z, Gadde S, Figeys D et al: An autocrine inflammatory forward-feedback loop after chemotherapy withdrawal facilitates the repopulation of drug-resistant breast cancer cells. CELL DEATH DIS 2017, 8(7):e2932.

43. Fernando RI, Hamilton DH, Dominguez C, David JM, McCampbell KK, Palena C: IL-8 signaling is involved in resistance of lung carcinoma cells to erlotinib. Oncotarget 2016, 7(27):42031-42044. 
44. Gyorffy B, Surowiak P, Budczies J, Lanczky A: Online survival analysis software to assess the prognostic value of biomarkers using transcriptomic data in non-small-cell lung cancer. PLOS ONE 2013, 8(12):e82241.

45. Wamsley JJ, Kumar M, Allison DF, Clift SH, Holzknecht CM, Szymura SJ, Hoang SA, Xu X, Moskaluk CA, Jones DR et al: Activin upregulation by NF-kappaB is required to maintain mesenchymal features of cancer stem-like cells in non-small cell lung cancer. CANCER RES 2015, 75(2):426-435.

46. Giraud J, Failla LM, Pascussi JM, Lagerqvist EL, Ollier J, Finetti P, Bertucci F, Ya C, Gasmi I, Bourgaux JF et al: Autocrine Secretion of Progastrin Promotes the Survival and Self-Renewal of Colon Cancer Stem-like Cells. CANCER RES 2016, 76(12):3618-3628.

47. Bray F, Ferlay J, Soerjomataram I, Siegel RL, Torre LA, Jemal A: Global cancer statistics 2018: GLOBOCAN estimates of incidence and mortality worldwide for 36 cancers in 185 countries. $C A$ Cancer J Clin 2018, 68(6):394-424.

48. Yu KH, Berry GJ, Rubin DL, Re C, Altman RB, Snyder M: Association of Omics Features with Histopathology Patterns in Lung Adenocarcinoma. CELL SYST 2017, 5(6):620-627.

49. Yoshizawa A, Sumiyoshi S, Sonobe M, Kobayashi M, Fujimoto M, Kawakami F, Tsuruyama T, Travis WD, Date $\mathrm{H}$, Haga $\mathrm{H}$ : Validation of the IASLC/ATS/ERS lung adenocarcinoma classification for prognosis and association with EGFR and KRAS gene mutations: analysis of $\mathbf{4 4 0}$ Japanese patients. J THORAC ONCOL 2013, 8(1):52-61.

50. Liu W, Ouyang S, Zhou Z, Wang M, Wang T, Qi Y, Zhao C, Chen K, Dai L: Identification of genes associated with cancer progression and prognosis in lung adenocarcinoma: Analyses based on microarray from Oncomine and The Cancer Genome Atlas databases. Mol Genet Genomic Med 2019, 7(2):e528.

51. Devarakonda S, Morgensztern D, Govindan R: Genomic alterations in lung adenocarcinoma. LANCET ONCOL 2015, 16(7):e342-e351.

52. Greulich H, Chen TH, Feng W, Janne PA, Alvarez JV, Zappaterra M, Bulmer SE, Frank DA, Hahn WC, Sellers WR et al: Oncogenic transformation by inhibitor-sensitive and -resistant EGFR mutants. PLOS MED 2005, 2(11):e313.

53. Wei Y, Zou Z, Becker N, Anderson M, Sumpter R, Xiao G, Kinch L, Koduru P, Christudass CS, Veltri RW et al: EGFR-mediated Beclin 1 phosphorylation in autophagy suppression, tumor progression, and tumor chemoresistance. CELL 2013, 154(6):1269-1284.

54. Han B, Jin B, Chu T, Niu Y, Dong Y, Xu J, Gu A, Zhong H, Wang H, Zhang X et al: Combination of chemotherapy and gefitinib as first-line treatment for patients with advanced lung adenocarcinoma and sensitive EGFR mutations: A randomized controlled trial. INT J CANCER 2017, 141(6):12491256.

55. Li S, Zhou F, Ren S, Zhou C: Response to pemetrexed rechallenge after acquired resistance of EGFRTKI in a patient with advanced NSCLC. LUNG CANCER 2014, 84(2):203-205.

56. Mok T, Kim SW, Wu YL, Nakagawa K, Yang JJ, Ahn MJ, Wang J, Yang JC, Lu Y, Atagi S et al: Gefitinib Plus Chemotherapy Versus Chemotherapy in Epidermal Growth Factor Receptor Mutation-Positive 
Non-Small-Cell Lung Cancer Resistant to First-Line Gefitinib (IMPRESS): Overall Survival and Biomarker Analyses. J CLIN ONCOL 2017, 35(36):4027-4034.

57. Yun CH, Mengwasser KE, Toms AV, Woo MS, Greulich H, Wong KK, Meyerson M, Eck MJ: The T790M mutation in EGFR kinase causes drug resistance by increasing the affinity for ATP. Proc Natl Acad Sci U S A 2008, 105(6):2070-2075.

58. Papadimitrakopoulou VA, Han JY, Ahn MJ, Ramalingam SS, Delmonte A, Hsia TC, Laskin J, Kim SW, $\mathrm{He} Y$, Tsai CM et al: Epidermal growth factor receptor mutation analysis in tissue and plasma from the AURA3 trial: Osimertinib versus platinum-pemetrexed for T790M mutation-positive advanced non-small cell lung cancer. CANCER-AM CANCER SOC 2020, 126(2):373-380.

59. Mok TS, Wu Y, Ahn M, Garassino MC, Kim HR, Ramalingam SS, Shepherd FA, He Y, Akamatsu H, Theelen WS et al: Osimertinib or Platinum-Pemetrexed in EGFR T790M-Positive Lung Cancer. N Engl J Med 2017, 376(7):629-640.

60. Oxnard GR, Hu Y, Mileham KF, Husain H, Costa DB, Tracy P, Feeney N, Sholl LM, Dahlberg SE, Redig AJ et al: Assessment of Resistance Mechanisms and Clinical Implications in Patients With EGFR T790M-Positive Lung Cancer and Acquired Resistance to Osimertinib. JAMA ONCOL 2018, 4(11):1527-1534.

61. Combo Therapy Beats Back Relapsed NSCLC. CANCER DISCOV 2019, 9(6):685.

62. To C, Jang J, Chen T, Park E, Mushajiang M, De Clercq D, Xu M, Wang S, Cameron MD, Heppner DE et al: Single and Dual Targeting of Mutant EGFR with an Allosteric Inhibitor. CANCER DISCOV2019, 9(7):926-943.

63. Janne PA, Wang X, Socinski MA, Crawford J, Stinchcombe TE, Gu L, Capelletti M, Edelman MJ, Villalona-Calero MA, Kratzke $\mathrm{R}$ et al: Randomized phase II trial of erlotinib alone or with carboplatin and paclitaxel in patients who were never or light former smokers with advanced lung adenocarcinoma: CALGB 30406 trial. J CLIN ONCOL 2012, 30(17):2063-2069.

64. Chong Y, Liu Y, Lu S, Cai B, Qin H, Chang CS, Ren M, Cowell JK, Hu T: Critical individual roles of the BCR and FGFR1 kinase domains in BCR-FGFR1-driven stem cell leukemia/lymphoma syndrome. INT J CANCER 2020, 146(8):2243-2254.

65. Sun B, Jensen NR, Chung D, Yang M, LaRue AC, Cheung HW, Wang Q: Synergistic effects of SHP2 and PI3K pathway inhibitors in GAB2-overexpressing ovarian cancer. AM J CANCER RES 2019, 9(1):145-159.

66. Leung C, Tong M, Chung K, Zhou L, Che N, Tang KH, Ding J, Lau E, Ng I, Ma S et al: Overriding Adaptive Resistance to Sorafenib Through Combination Therapy With Src Homology 2 DomainContaining Phosphatase 2 Blockade in Hepatocellular Carcinoma. HEPATOLOGY 2019.

67. Jiang $L, X u W, C h e n Y, Z$ hang $Y$ : SHP2 inhibitor specifically suppresses the stemness of KRASmutant non-small cell lung cancer cells. Artif Cells Nanomed Biotechnol 2019, 47(1):3231-3238.

68. Lu H, Liu C, Velazquez R, Wang H, DunkI LM, Kazic-Legueux M, Haberkorn A, Billy E, Manchado E, Brachmann SM et al: SHP2 Inhibition Overcomes RTK-Mediated Pathway Reactivation in KRASMutant Tumors Treated with MEK Inhibitors. MOL CANCER THER 2019, 18(7):1323-1334. 
69. Dardaei L, Wang HQ, Singh M, Fordjour P, Shaw KX, Yoda S, Kerr G, Yu K, Liang J, Cao Y et al: SHP2 inhibition restores sensitivity in ALK-rearranged non-small-cell lung cancer resistant to ALK inhibitors. NAT MED 2018, 24(4):512-517.

70. Jiang L, Xu W, Chen Y, Zhang Y: SHP2 inhibitor specifically suppresses the stemness of KRASmutant non-small cell lung cancer cells. Artif Cells Nanomed Biotechnol 2019, 47(1):3231-3238.

71. Xiang D, Cheng Z, Liu H, Wang X, Han T, Sun W, Li X, Yang W, Chen C, Xia M et al: Shp2 promotes liver cancer stem cell expansion by augmenting beta-catenin signaling and predicts chemotherapeutic response of patients. HEPATOLOGY 2017, 65(5):1566-1580.

72. Roccograndi L, Binder ZA, Zhang L, Aceto N, Zhang Z, Bentires-Alj M, Nakano I, Dahmane N, O'Rourke DM: SHP2 regulates proliferation and tumorigenicity of glioma stem cells. J Neuroonco/ 2017, 135(3):487-496.

73. Dong L, Yu WM, Zheng H, Loh ML, Bunting ST, Pauly M, Huang G, Zhou M, Broxmeyer HE, Scadden DT et al: Leukaemogenic effects of Ptpn11 activating mutations in the stem cell microenvironment. NATURE 2016, 539(7628):304-308.

74. Griger J, Schneider R, Lahmann I, Schowel V, Keller C, Spuler S, Nazare M, Birchmeier C: Loss of Ptpn11 (Shp2) drives satellite cells into quiescence. ELIFE 2017, 6.

75. Leon G, MacDonagh L, Finn SP, Cuffe S, Barr MP: Cancer stem cells in drug resistant lung cancer: Targeting cell surface markers and signaling pathways. Pharmacol Ther 2016, 158:71-90.

76. Tammela T, Sanchez-Rivera FJ, Cetinbas NM, Wu K, Joshi NS, Helenius K, Park Y, Azimi R, Kerper NR, Wesselhoeft RA et al: A Wnt-producing niche drives proliferative potential and progression in lung adenocarcinoma. NATURE 2017, 545(7654):355-359.

77. Luo X, Liao R, Hanley KL, Zhu HH, Malo KN, Hernandez C, Wei X, Varki NM, Alderson N, Chu C et al: Dual Shp2 and Pten Deficiencies Promote Non-alcoholic Steatohepatitis and Genesis of Liver TumorInitiating Cells. CELL REP 2016, 17(11):2979-2993.

78. Bhattacharyya S, Feferman L, Tobacman JK: Chondroitin sulfatases differentially regulate Wnt signaling in prostate stem cells through effects on SHP2, phospho-ERK1/2, and Dickkopf Wnt signaling pathway inhibitor (DKK3). Oncotarget 2017, 8(59):100242-100260.

79. Goffart N, Kroonen J, Rogister B: Glioblastoma-initiating cells: relationship with neural stem cells and the micro-environment. Cancers (Basel) 2013, 5(3):1049-1071.

80. Thomas TM, Yu JS: Metabolic regulation of glioma stem-like cells in the tumor micro-environment. CANCER LETT 2017, 408:174-181.

81. Ouspenskaia T, Matos I, Mertz AF, Fiore VF, Fuchs E: WNT-SHH Antagonism Specifies and Expands Stem Cells prior to Niche Formation. CELL 2016, 164(1-2):156-169.

82. Chou YF, Chen HH, Eijpe M, Yabuuchi A, Chenoweth JG, Tesar P, Lu J, McKay RD, Geijsen N: The growth factor environment defines distinct pluripotent ground states in novel blastocyst-derived stem cells. CELL 2008, 135(3):449-461.

83. Herjan T, Hong L, Bubenik J, Bulek K, Qian W, Liu C, Li X, Chen X, Yang H, Ouyang S et al: IL-17receptor-associated adaptor Act1 directly stabilizes mRNAs to mediate IL-17 inflammatory signaling. 
NAT IMMUNOL 2018, 19(4):354-365.

84. Kawano M, Tanaka K, Itonaga I, Iwasaki T, Tsumura H: Interaction between human osteosarcoma and mesenchymal stem cells via an interleukin-8 signaling loop in the tumor microenvironment. CELL COMMUN SIGNAL 2018, 16(1):13.

85. Pasquier J, Vidal F, Hoarau-Vechot J, Bonneau C, Darai E, Touboul C, Rafii A: Surgical peritoneal stress creates a pro-metastatic niche promoting resistance to apoptosis via IL-8. J TRANSL MED 2018, 16(1):271.

86. Liubomirski Y, Lerrer S, Meshel T, Rubinstein-Achiasaf L, Morein D, Wiemann S, Korner C, Ben-Baruch A: Tumor-Stroma-Inflammation Networks Promote Pro-metastatic Chemokines and Aggressiveness Characteristics in Triple-Negative Breast Cancer. FRONT IMMUNOL 2019, 10:757.

87. Lee JS, Kang JH, Boo HJ, Hwang SJ, Hong S, Lee SC, Park YJ, Chung TM, Youn H, Mi LS et al: STAT3-mediated IGF-2 secretion in the tumour microenvironment elicits innate resistance to anti-IGF1R antibody. NAT COMMUN 2015, 6:8499.

88. Shimizu M, Tanaka N: IL-8-induced O-GIcNAc modification via GLUT3 and GFAT regulates cancer stem cell-like properties in colon and lung cancer cells. ONCOGENE 2019, 38(9):1520-1533.

89. Kahraman DC, Kahraman T, Cetin-Atalay R: Targeting PI3K/Akt/mTOR Pathway Identifies Differential Expression and Functional Role of IL8 in Liver Cancer Stem Cell Enrichment. MOL CANCER THER 2019, 18(11):2146-2157.

90. Ginestier C, Liu S, Diebel ME, Korkaya H, Luo M, Brown M, Wicinski J, Cabaud O, Charafe-Jauffret E, Birnbaum D et al: CXCR1 blockade selectively targets human breast cancer stem cells in vitro and in xenografts. J CLIN INVEST 2010, 120(2):485-497.

91. Korkaya H, Kim GI, Davis A, Malik F, Henry NL, Ithimakin S, Quraishi AA, Tawakkol N, D'Angelo R, Paulson AK et al: Activation of an IL6 inflammatory loop mediates trastuzumab resistance in HER2+ breast cancer by expanding the cancer stem cell population. MOL CELL 2012, 47(4):570-584.

92. He W, Luistro L, Carvajal D, Smith M, Nevins T, Yin X, Cai J, Higgins B, Kolinsky K, Rizzo C et al: High tumor levels of IL6 and IL8 abrogate preclinical efficacy of the gamma-secretase inhibitor, R04929097. MOL ONCOL 2011, 5(3):292-301.

93. Li FF, Shen J, Shen HJ, Zhang X, Cao R, Zhang Y, Qui Q, Lin XX, Xie YC, Zhang LH et al: Shp2 plays an important role in acute cigarette smoke-mediated lung inflammation. J IMMUNOL 2012, 189(6):3159-3167.

94. Liu YN, Chang TH, Tsai MF, Wu SG, Tsai TH, Chen HY, Yu SL, Yang JC, Shih JY: IL-8 confers resistance to EGFR inhibitors by inducing stem cell properties in lung cancer. Oncotarget 2015, 6(12):10415-10431.

95. Goldstein LJ, Perez RP, Yardley D, Han LK, Reuben JM, Gao H, McCanna S, Butler B, Ruffini PA, Liu Y et al: A window-of-opportunity trial of the CXCR1/2 inhibitor reparixin in operable HER-2-negative breast cancer. BREAST CANCER RES2020, 22(1):4.

96. Mamik MK, Ghorpade A: Src homology-2 domain-containing protein tyrosine phosphatase (SHP) 2 and p38 regulate the expression of chemokine CXCL8 in human astrocytes. PLOS ONE 2012, 
Figures

A

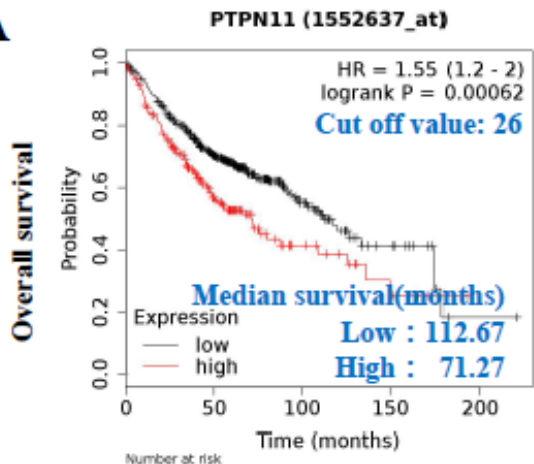

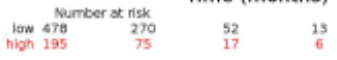

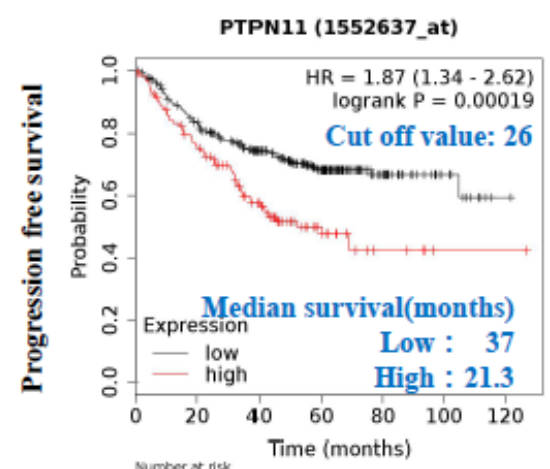

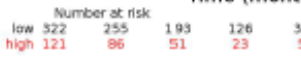

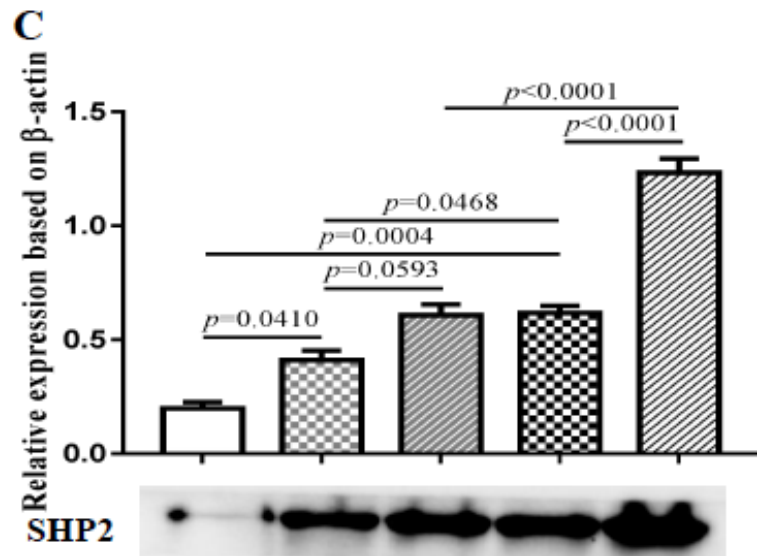

B
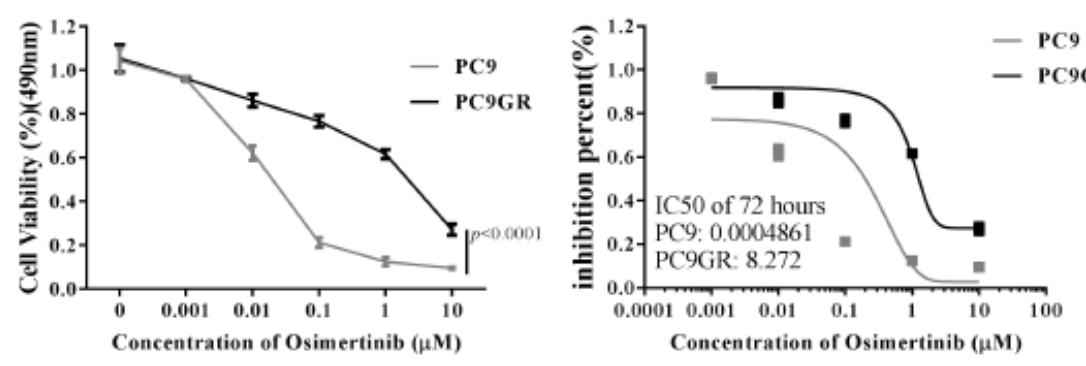

- PC9
- PC9GR $\beta$-actin

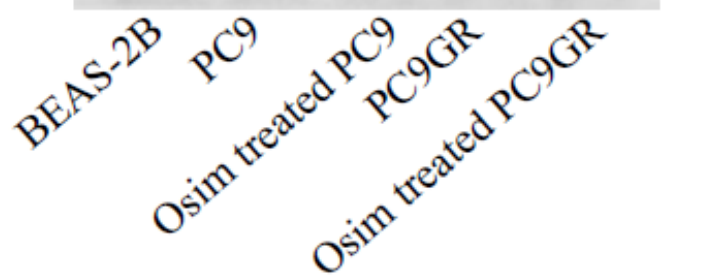

D

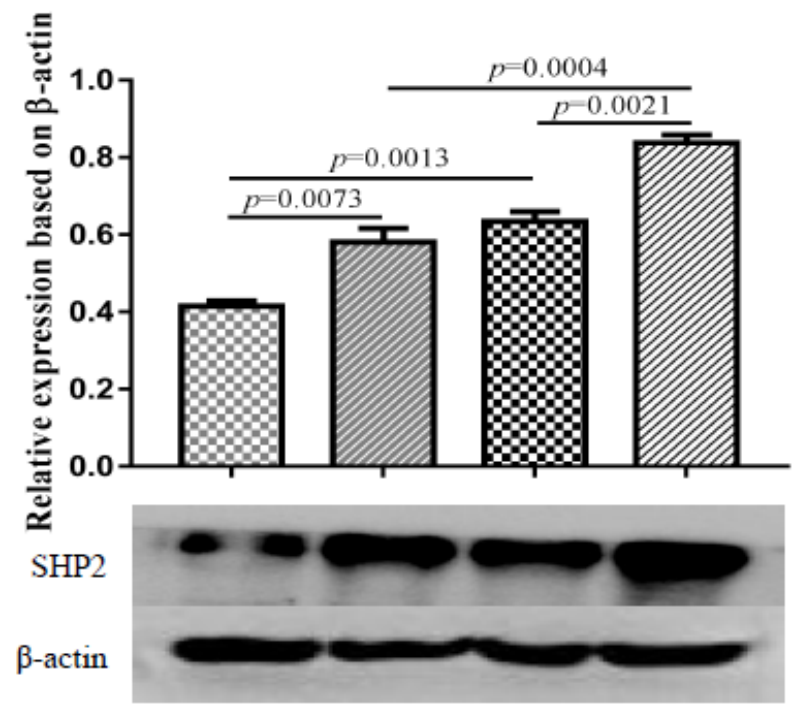

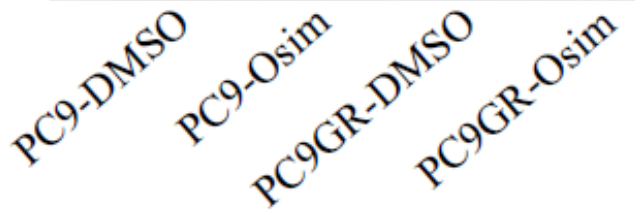

\section{Figure 1}

Figure caption not provided in this version. 


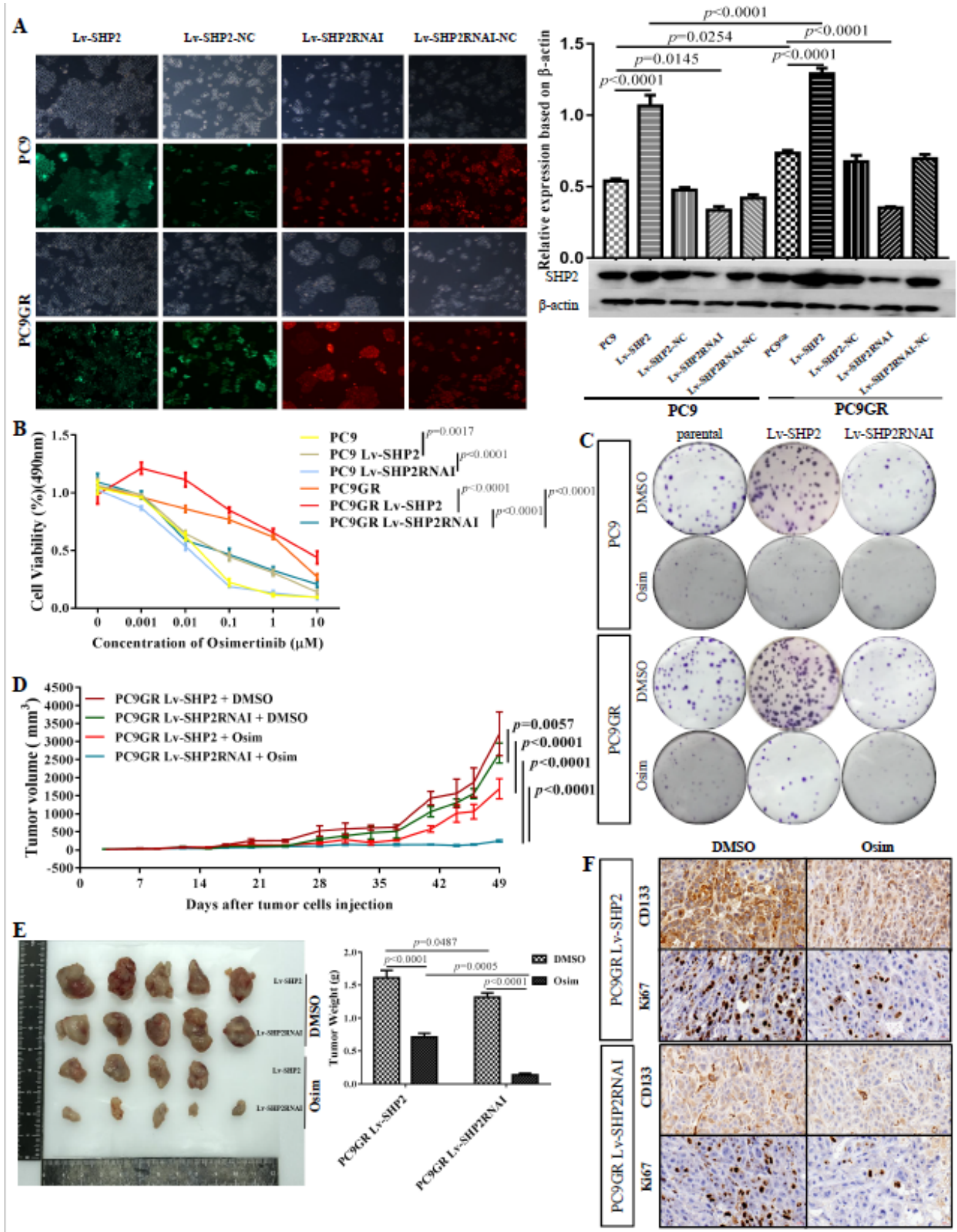

Figure 2

Figure caption not provided in this version. 
$\mathbf{A}$

PC9

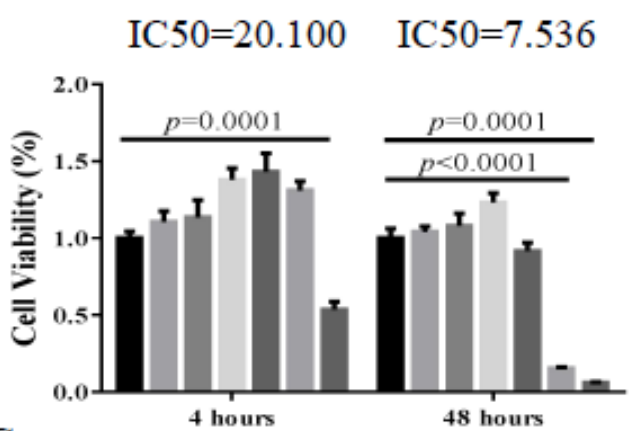

C

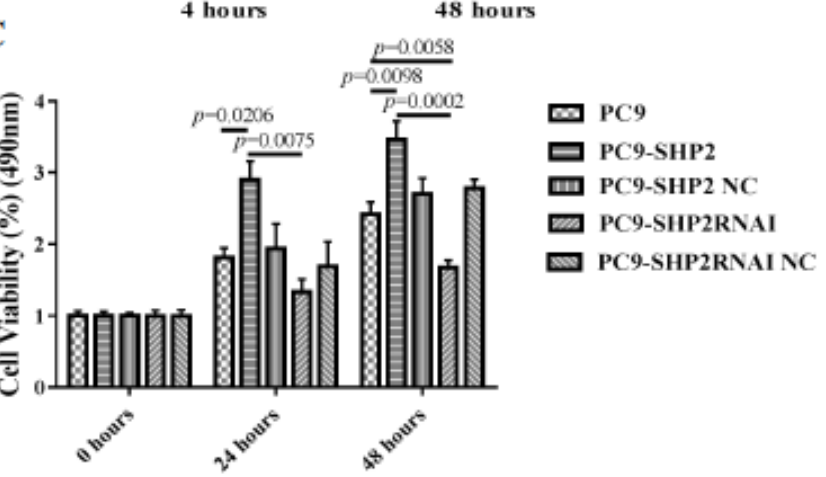

B

\section{PC9GR}
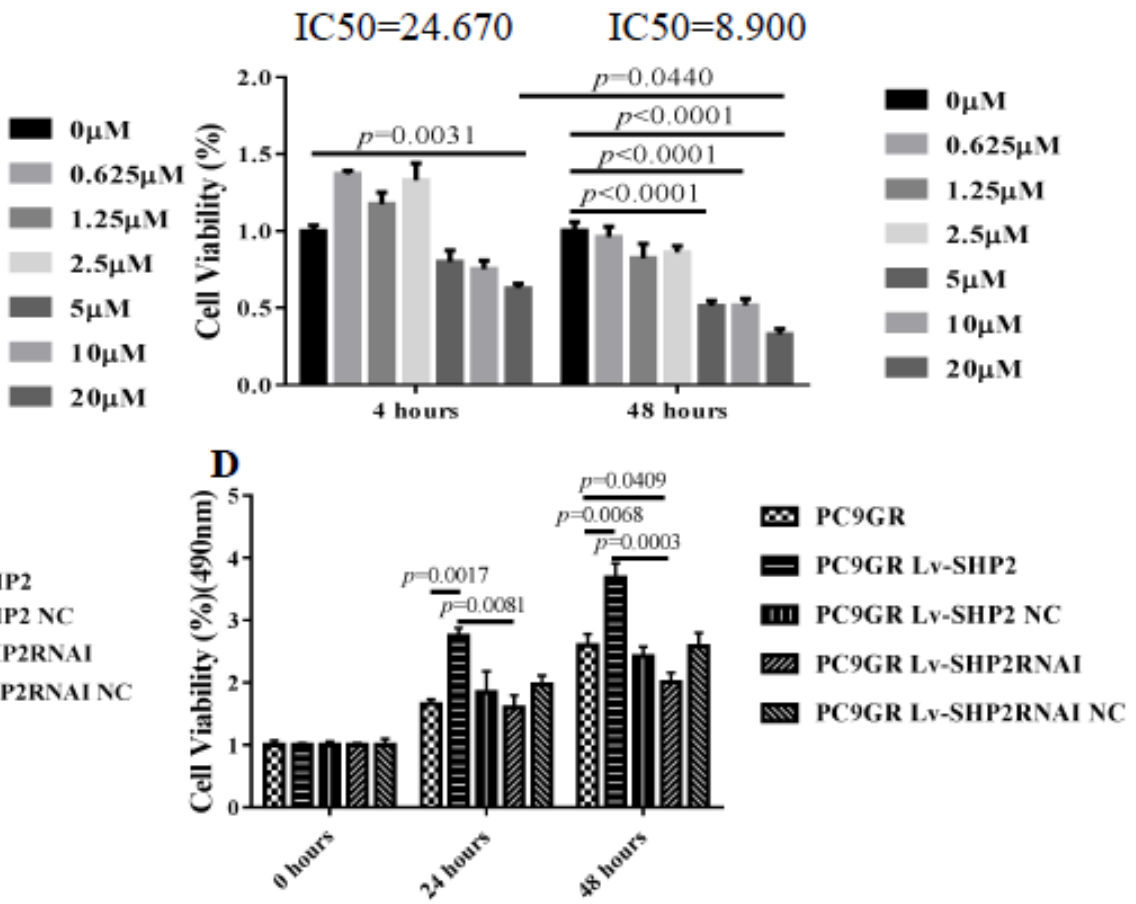
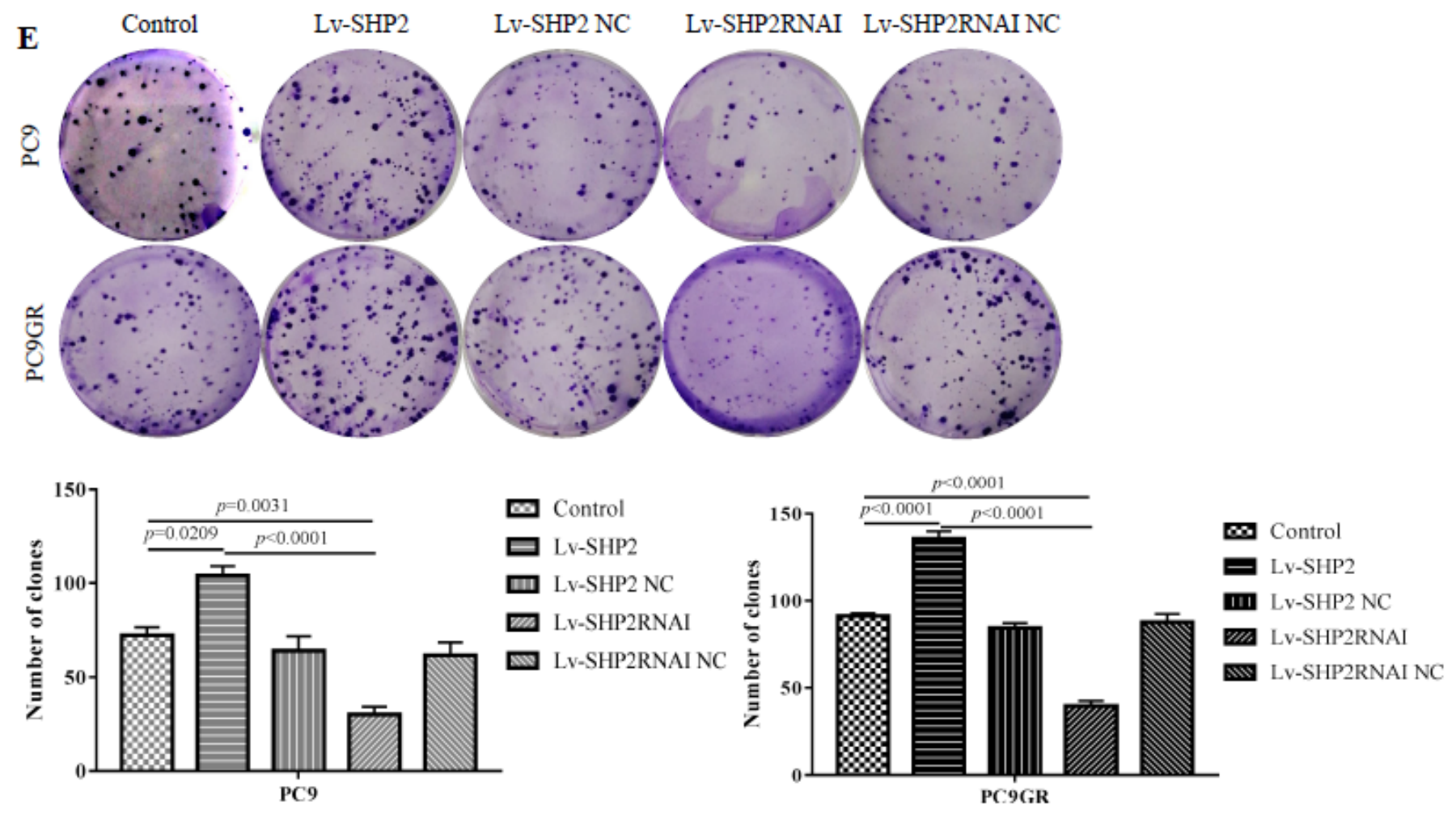

Figure 3

Figure caption not provided in this version. 


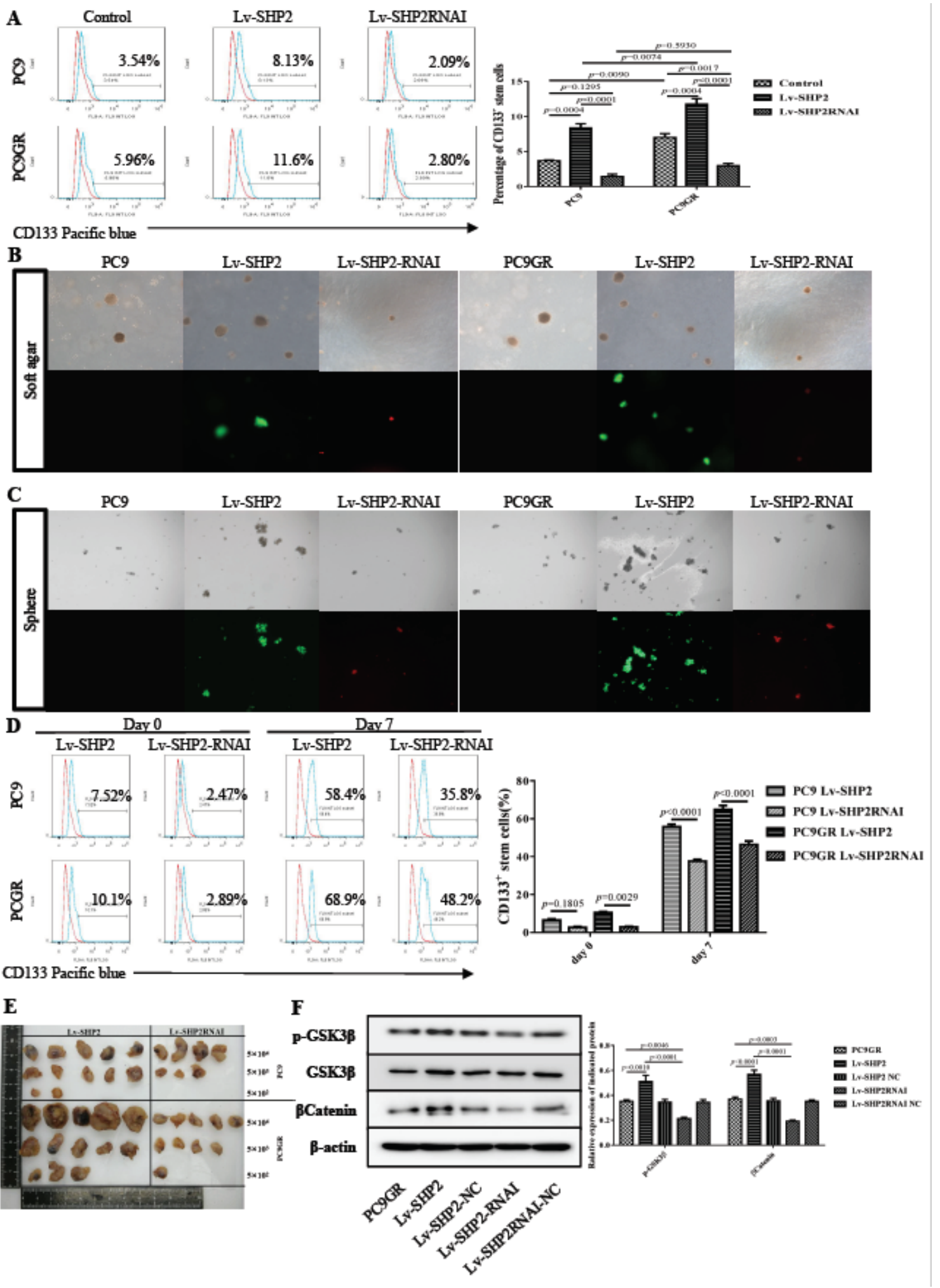

Figure 4

Figure caption not provided in this version. 
A
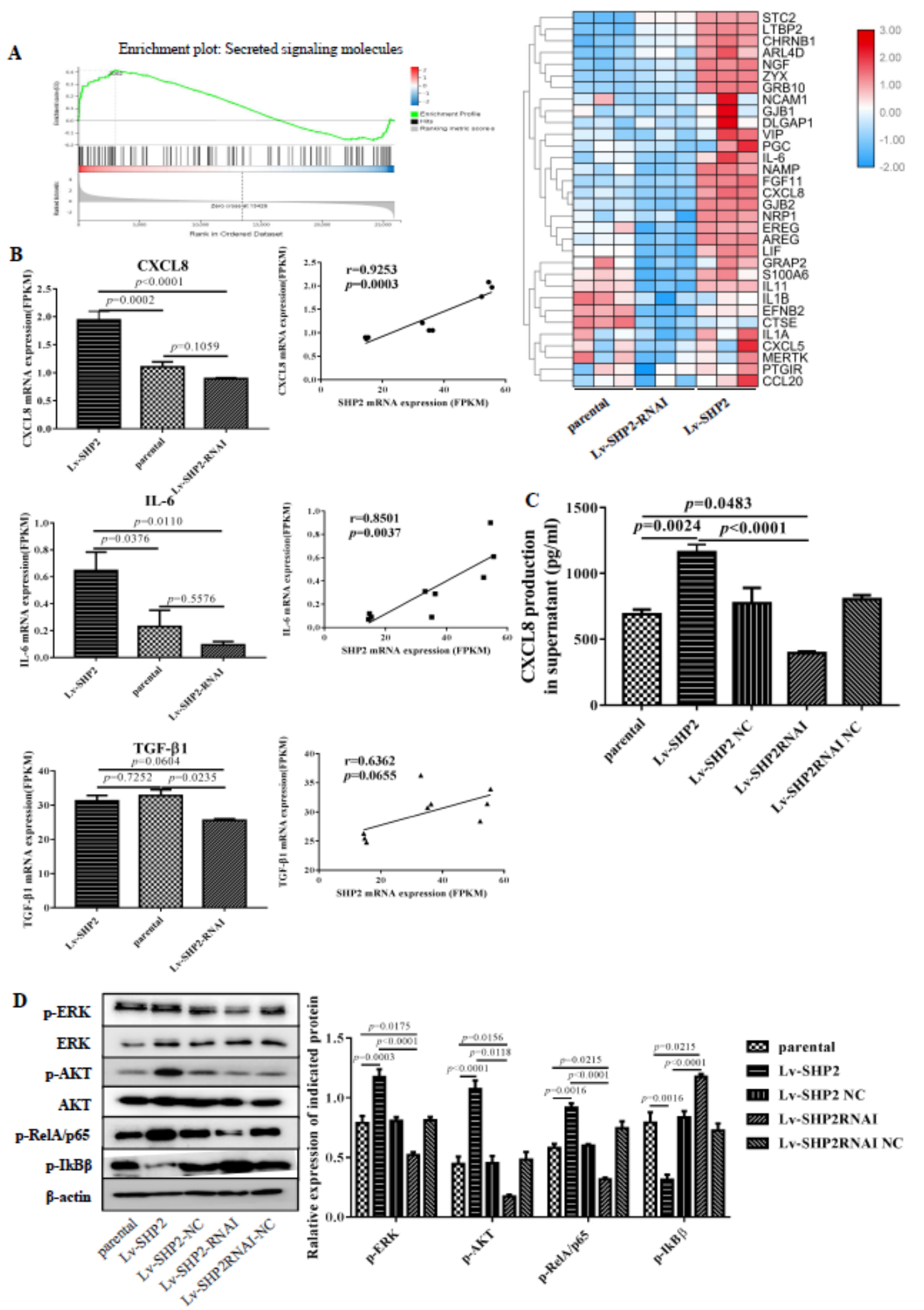

Figure 5

Figure caption not provided in this version. 

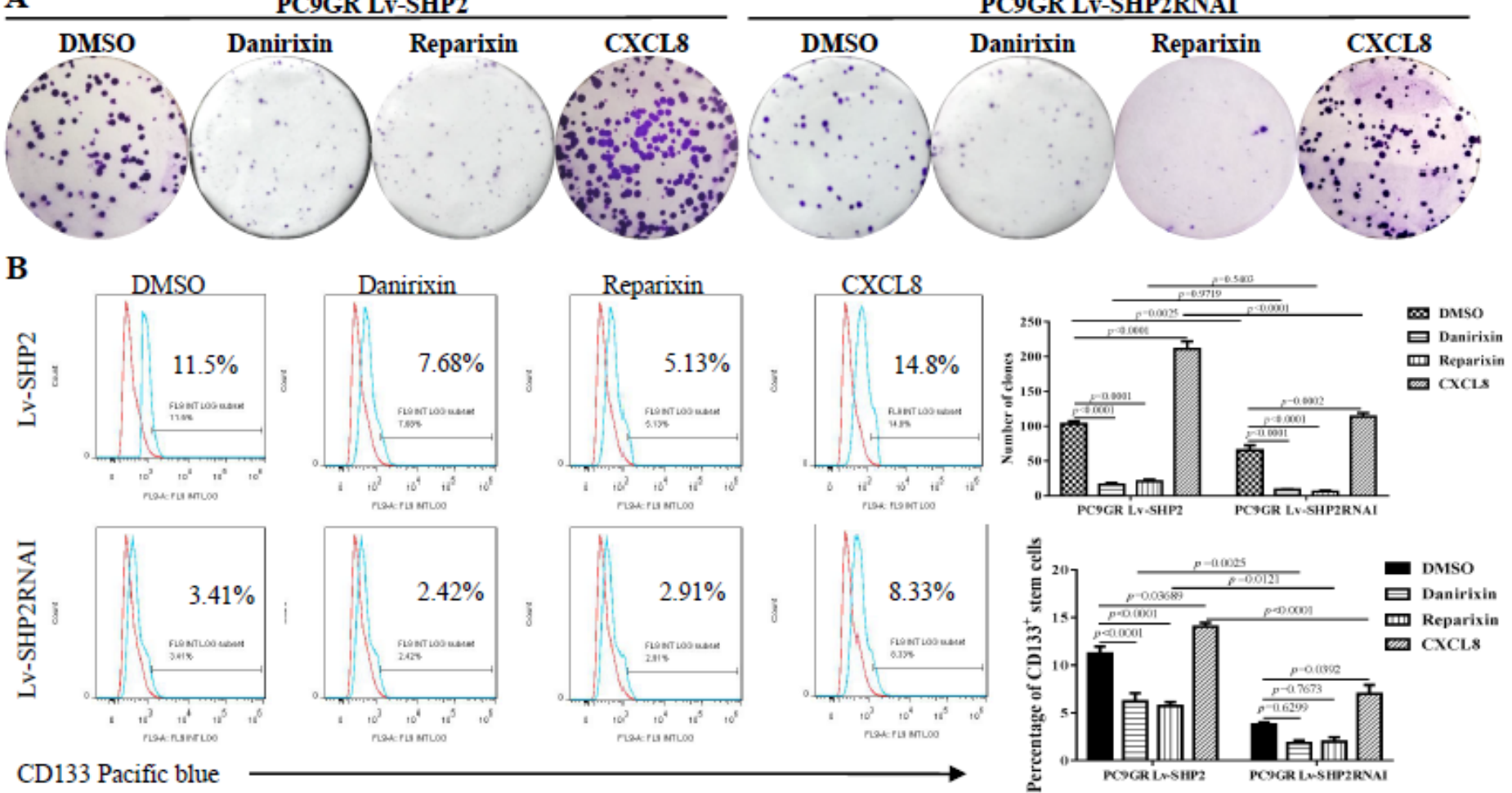

C
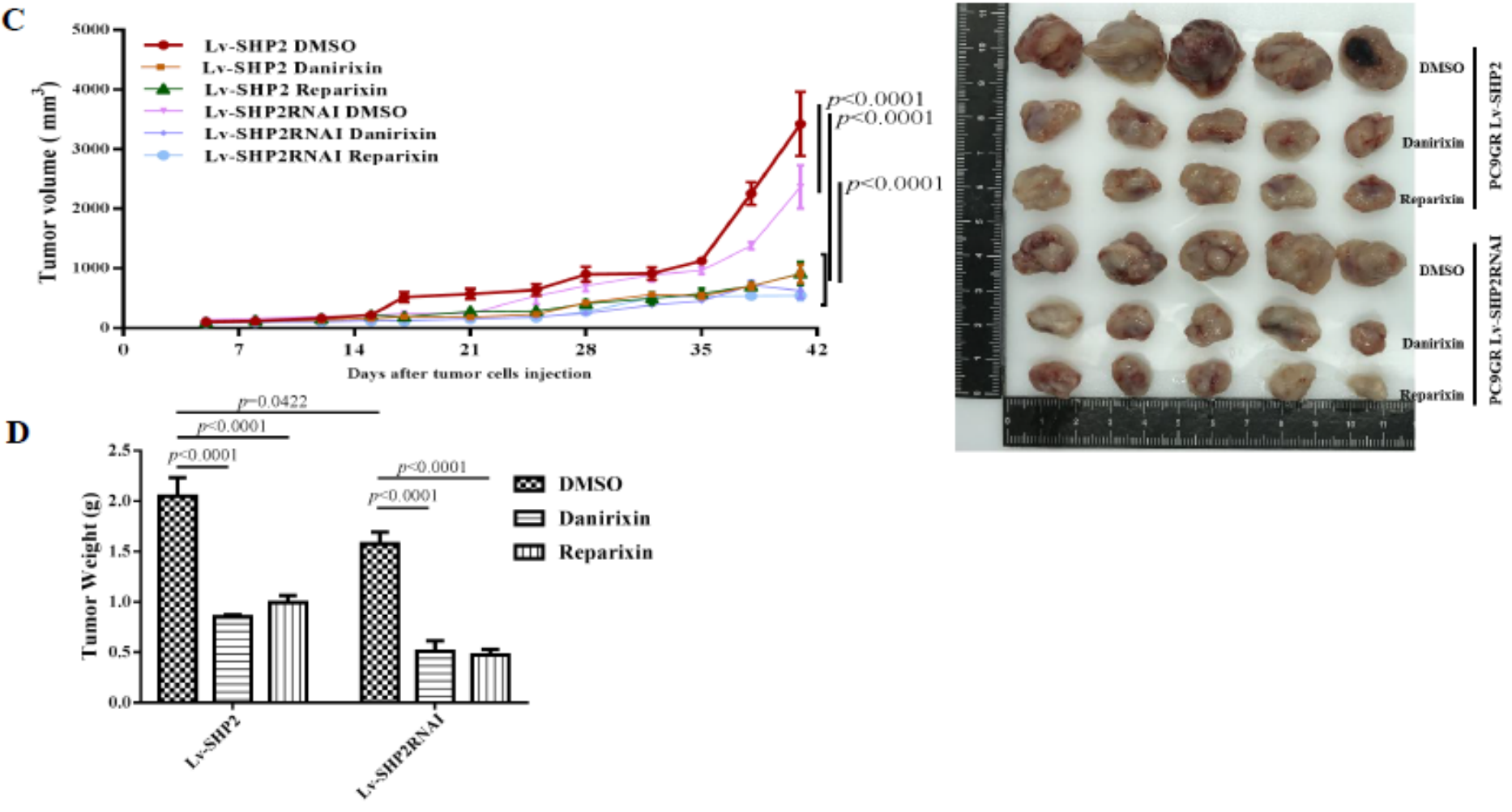

\section{Figure 6}

Figure caption not provided in this version. 


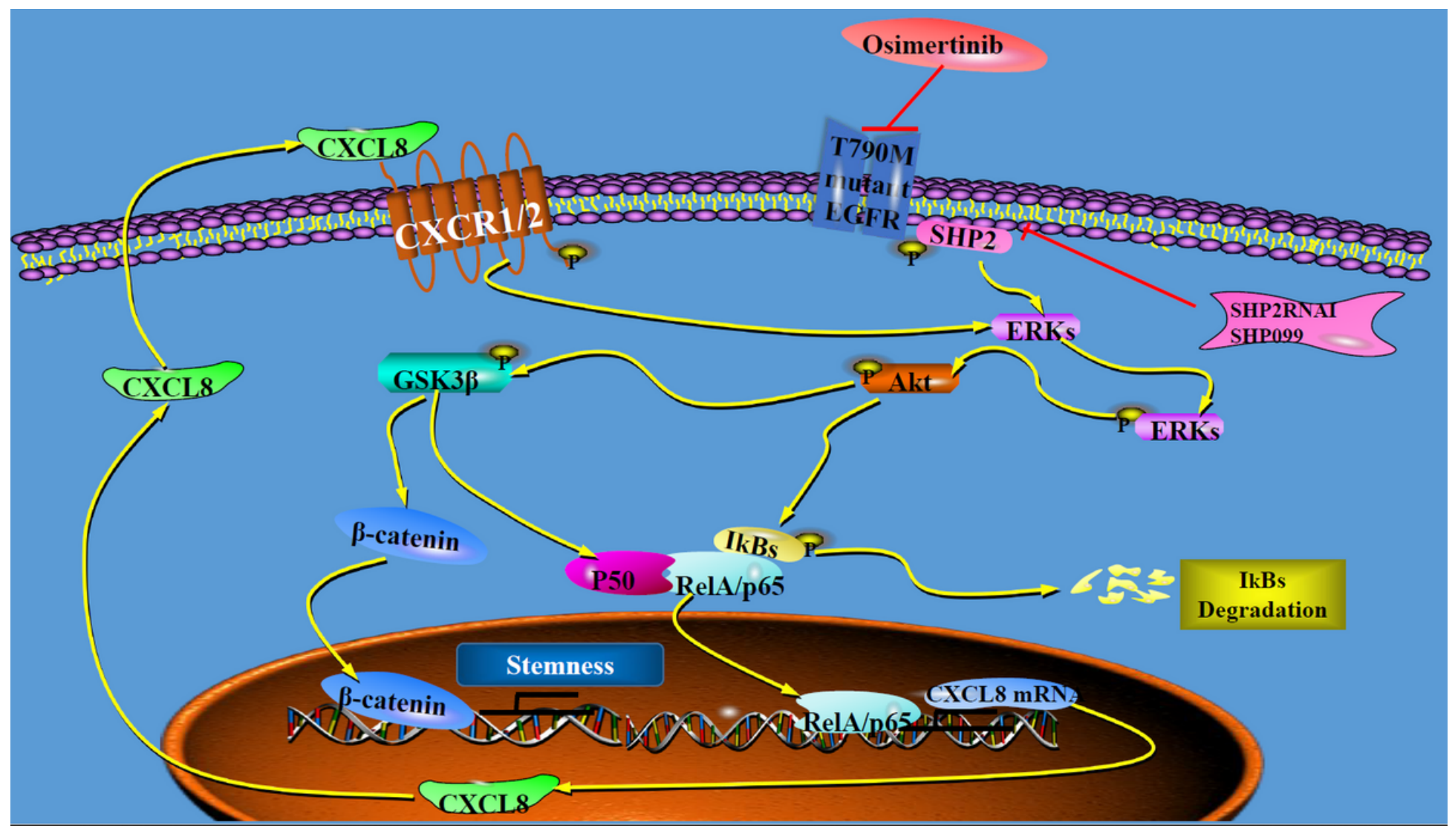

Figure 7

Figure caption not provided in this version.

\section{Supplementary Files}

This is a list of supplementary files associated with this preprint. Click to download.

- SupplementaryFigure1.pdf

- SupplementaryFigure2.pdf

- SupplementaryTable1.pdf

- SupplementaryTable2.pdf 